\title{
Wet-deck slamming loads and pressures acting on wave piercing catamarans
}

Babak Shabani ${ }^{\text {a, }}$, Jason Lavroff a , Damien S Holloway ${ }^{a}$, Michael R Davis ${ }^{a}$ and Giles A Thomas ${ }^{b}$

a School of Engineering, University of Tasmania, Australia

${ }^{\mathrm{b}}$ Department of Mechanical Engineering, University College London, England, United Kingdom

*Corresponding author. Email address: babak.shabani@utas.edu.au; Address:

School of Engineering, College of Sciences and Engineering, University of

Tasmania, Dobson Rd, Sandy Bay, TAS, 7005, T: +61 36226 2137, F: +61 3

62267247 


\begin{abstract}
BACKGROUND: The wet-deck height and centre bow configuration in wave piercing catamarans are critical design factors which influence slamming occurrence and severity.
\end{abstract}

OBJECTIVE: In this paper, the wet-deck slamming loads and pressures acting on a 112 m catamaran with a centre bow were investigated in regular waves in two wave heights.

METHODS: A 2.5 m hydroelastic model with three alternate configurations of wet-deck vertical clearance was tested at a speed of $2.89 \mathrm{~m} / \mathrm{s}$ (38 knots full-scale equivalent).

RESULTS: The results showed that at the instant of slamming the centre bow immersion depth relative to the undisturbed incident wave elevation was less than two thirds of the maximum immersion depth during the wet-deck slam event. The location of maximum slamming pressure was found to be in the range between $77 \%$ and $80 \%$ of the overall length from the transom. The relationship between the relative velocity at impact and slamming force indicated that slamming loads in the order of the vessel weight can occur for the parent design when the relative velocity at slam is about a quarter of the forward speed.

CONCLUSIONS: Overall, increasing the wet-deck height was more beneficial for reduction of slamming loads and pressures in smaller waves than in large waves.

Key words: wave piercing catamaran, hydroelastic segmented model, center bow, wetdeck height, slamming loads, slamming pressures, relative velocity 


\section{Introduction}

This paper reports on an investigation into the effect of the centre bow design and tunnel clearance on the severity of slamming loads and pressures acting on a Wave Piercing Catamaran (WPC) as shown in Figure 1. Improving the seakeeping performance of high speed catamaran ferries was one of the earliest development stages of these vessels [1-4]. For WPC vessels, the role of centre bow is to provide reserve buoyancy in the forward area $[5,6]$ where the demi-hulls are extremely slender to restrict pitch motions in extreme pitch-in scenarios. Therefore WPCs are less prone to deck-diving than conventional catamarans with a flat cross-deck bow structure [7, 8]. However, wet deck slamming in the bow area [9, 10] does occur for both conventional catamarans and WPCs. At high wave encounter frequencies, where hull motions are small, the centre bow can interact with the water contributing to full or partial arch filling resulting in bow loads which are typically of relatively small magnitude [6]. The arch filling or closure here is referred to as the short interval during which the water rises beneath the arch tops between the demi-hulls and the short centre bow and fills the cross section prior to the instant of slamming.

Class societies have different approaches for the calculation of design slamming pressure for wave piercing catamarans. Lloyd's Register rules for special service craft (SSC), for example, provide general empirical formulae to determine wetdeck impact pressure according to the operational conditions such as forward speed, wave height and relative impact velocity. These also include some centre bow design parameters, such as effective arch clearance in WPCs and protected centre bow area [11]. In contrast, Det Norske Veritas \& Germanischer Lloyd (DNV GL) rules for high speed and light craft provide a general procedure to calculate slamming pressure acting on flat-wet deck catamarans, while the determination of local design impact pressure with special designs, such as WPCs with a centre bow, is referred to as other direct design methods such as model tests or full-scale trials [12].

The archway clearance (i.e. the vertical distance from the waterline to the top of the archway between the demihull and the centre bow) is a critical design factor 
influencing wet-deck slamming occurrence. The evaluation of slamming occurrence based on kinematic conditions is the classic approach [13-15]. For WPCs, Lavroff and Davis [6] provided a kinematic analysis for centre bow immersion and presented a two-dimensional criterion that indicates slamming occurrence in regular waves. This refers to the definition of a sectional arch filling height at which the displaced water by the centre bow and demi-hulls fills the gap between the arched wet-deck and the undisturbed waterline within the archways. Such a technique can be combined with seakeeping codes for high speed catamarans such as those developed by Davis et al. $[16,17]$ to identify slamming occurrences in random waves as a consequence of extreme relative motion [18]. The design objective is elimination or minimisation of slamming occurrences at specified operating conditions. For WPCs and other catamarans, although increasing the vertical clearance between the water surface and the cross deck structure seems to be a possible solution to avoid slamming, the full elimination of slamming occurrence may not be expected because of the increased relative motions and water pile up in the enclosed parts of the cross deck structure between demihulls. For WPCs, the latter corresponds to the deck structure within the archways where the centre bow is surrounded by demihulls. Since relative vertical displacements in waves are also large in the centre bow area, it is less likely that slamming can be avoided when waves become larger [19, 20]. If slamming cannot be avoided, the calculation of arch slamming pressure and evaluation of structural design with respect to the vessel's operational conditions are necessary for class approvals [11]. However, it should be noted that the WPC design does virtually prevent deck diving which can lead to far more serious damage [5, 7].

The published work for ship slamming loads and pressures is very broad, as reviewed by [21] and [22] and more recently by [23] and [24]. The most common theoretical approach for calculating slamming pressures is based on water entry models [25, 26]. However, experimental techniques are still considered the best approach in the field while numerical CFD techniques are being developed. Examples of relevant studies for motion and wet-deck slamming in catamarans can be found in [27-36]. 
Despite the numerous investigations for WPCs as mentioned above, the variation of slamming pressure and loads due to the variations of wet-deck height and consequently archway clearance has not yet been fully investigated. Although it is evident from the relevant classification rules that the increase of the wet-deck clearance is a potential solution to reduce the impact pressure [11, 12], such reduction, if achieved, cannot yet be quantified with certainty during the design process of WPCs with a centre bow. This is due to the lack of relevant experimental data or unavailability of any established theoretical/numerical approach in consideration of the effect of the wet-deck height on slamming loads and pressures. In this paper, the relationship between the relative velocity at impact and slamming force is investigated to provide experimental data to support early stage design considerations in WPCs.

\section{Hydroelastic catamaran model, instrumentation, and model test conditions}

\subsection{The segmented catamaran model with an adjustable wet-deck configuration}

A photograph of the $2.5 \mathrm{~m}$ catamaran model (with a scale factor of 1:44.8) used in model tests is shown in Figure 2. Figure 3 shows a schematic view of the model showing the location and type of sensors installed, including load cells, accelerometers and pressure transducers in the centre bow area. The model displacement was set to $27.12 \mathrm{~kg}$, equivalent to 2500 tonnes at full-scale. Table 1 provides the model specifications, and a full list of the instrumentation is given in Table 2.

As shown in Figure 3, the demihulls of the catamaran model within the aft, middle and forward segments are connected with longitudinal backbone beams, while the centre bow (CB) segment is only connected to the forward segment demihulls by two transverse beams. The centre bow segment was mounted on these two beams with two ATI load cells placed on the centre line to measure load exchanges between the CB segment and each transverse beam. In addition to the two ATI load cells, to account for slamming loads, two Brüel \& Kjær accelerometers and an 
array of 18 Endevco piezoresistive pressure transducers (8510C series) were installed on the CB segment to measure slamming accelerations and pressures acting on the CB segment. Four short elastic links made from aluminium with similar cross sections were used to connect the segmented demihulls. The dimensions of the links were designed so that the full-scale whipping response at approximately $2.4 \mathrm{~Hz}$ in wet mode could be simulated in the model with a scaled frequency of $13.8 \mathrm{~Hz}[37,38]$.

Two wave probes were fitted below the carriage to measure the variations of water surface at two positions during the test. The first point was aligned with the model LCG, and the second point was $1 \mathrm{~m}$ forward of the LCG. Both wave probes were offset from the model centerline by approximately $1.35 \mathrm{~m}$ on opposite sides. Using video recording and also the recorded data, it was found the measurements could mainly be used for wave phase rather than the amplitude. The moving wave probes consisted of two slender cylindrical rods supported by an aluminium backbone which was partly submerged. This resulted in unreliable wave profile in terms of amplitude and thus the amplitudes were assumed to be equal to that measured by a stationary wave probe [20].

The wet-deck clearance of the model was designed to be adjustable, allowing an increase or decrease of the aft and middle deck segments, located between the transom and 33\% of the overall length ahead of the transom and between 33\% and $56 \%$ of overall length respectively. For wet-deck alignment with the forward segment, a new CB segment was designed and constructed according to the adjusted wet-deck height and centre bow design requirements [39]. The development and construction of the 2.5 m hydroelastic segmented catamaran model (HSM02) with the adjustable wet-deck feature followed broadly the work by Lavroff [40] and is fully described by Shahraki [41].

\subsection{Design of various centre bow and wet-deck configurations}

Three centre bow and wet-deck configurations were considered in this study. Figure 4 compares the cross sections of these configurations, designated as the 
high $\mathrm{CB}$, parent $\mathrm{CB}$ and low $\mathrm{CB}$. The $\mathrm{CB}$ was truncated at a longitudinal position of $76 \%$ of the length from the model transom. The keel of the centre bow is located slightly above the design waterline (DWL) shown in Figure 4. The tunnel height is equivalent to the wet-deck height and the dashed red lines are given to show the variations of the centre bow in three parts (The first, second and last third, according to the top arch height).

As compared in Table 3, the three centre bows have the same length but different tunnel and arch top clearances relative to a still waterline located at DWL. The tunnel clearances of the high, parent and low CBs are defined at the longitudinal position of the centre bow truncation section and are full-scale equivalent to $3.5 \mathrm{~m}$, $3.0 \mathrm{~m}$ and $2.3 \mathrm{~m}$, respectively. From the transom to the centre bow truncation at $76 \%$ of the length, the catamaran has a flat wet-deck configuration connecting the demihulls, except for a small portion of the length just aft of the CB in which the arch configurations on both sides gradually become flat. Similarly, the arch top clearance is defined at the centre bow truncation section at the transverse location in which the arch clearance is highest. The tunnel clearance is constant for the main flat wet deck, but the arch top height increases from the centre bow truncation toward the forward sections of the centre bow. Therefore the reference section for the bow arch top clearance is the CB truncation.

The vertical distance between the centre bow keel and the top of the arch is referred to as the arch height. The sum of the arch height and the centre bow keel clearance is also referred to as air gap $\left(G_{\mathrm{A}}\right)$ in Lloyd's rules [11] for wave piercing catamarans. However, it is mentioned that a maximum of only two thirds of the arch height should be taken into account for calculating the air gap when using the design rules. In these cases, the maximum air gaps $\mathrm{G}_{\mathrm{A}}$ (max.) at $\mathrm{CB}$ truncation for various designs are close to the tunnel clearances reported in Table 3. 


\subsection{Pressure transducers and signal conditioning}

Out of a total of 18 pressure transducers, 10 arch top pressure transducers were placed between $70 \%$ and $84 \%$ of the overall length from the transom while 4 inboard and 4 outboard transducers were placed between $76 \%$ and $80 \%$. These locations are schematically shown in Figure 3 in the plan view. Figure 5 also shows the vertical locations of the transducers for the parent CB. Longitudinally, the high and low CBs had similar transducer locations to the parent CB. Figure 6 shows the vertical locations of the arch top pressure transducers for different CB configurations, normalised by the draft at design waterline (DWL). In a transverse direction, the arch top pressure points are the horizontal tangent points, while the inboard and outboard pressure points have $10^{\circ}$ deadrise angles.

ENDEVCO DC amplifiers (model 136) were used for the signal conditioning of pressure transducers. These amplifiers have auto-zeroing and filtering features. The standard internal module (31875-1000) was used during the tests which uses a 4pole Butterworth low pass filter module with a corner frequency of $10 \mathrm{kHz}$. This can be increased up to $80 \mathrm{kHz}$ if the standard module is replaced with other modules. No software filtering was used when analyzing pressure data.

It is worth noting that Endevco piezoresistive pressure transducers have high sensitivity and high resonant frequency (320 kHz), making them appropriate for measuring dynamic pressures. They also have a stable characteristic over a wide temperature range and provide excellent linearity features. The face diameter of the pressure transducers is $3.8 \mathrm{~mm}$. The effects of environmental factors, such as temperature, light sensitivity, air entrapment and water ingress on the measured responses were not investigated independently and further investigations are recommended. However, it is not expected that these matters would affect the performance of the transducers since the operational manuals make no reference to these aspects. However, air entrapment will influence the actual slamming pressures, particularly in relation to scaling. In Section 4, further investigation on the effect of air entrapment within the archways and during the slamming is recommended as further work. 


\subsection{Model test program}

Model test conditions are listed in Table 4. Several model tests at various wave frequencies were performed for each test condition in the towing tank of the Australian Maritime College. Each condition here represents a series of tank tests at a given model speed and wave height and at multiple wave frequencies, ranging from 0.35 to $0.9 \mathrm{~Hz}$. The data obtained from the stationary wave probe are analysed to obtain measured wave heights and wave frequencies which are listed in Table 5. Time records of heave, pitch and wave profiles, pressure and centre bow loads were used for peak data analysis. The number of recorded wave encounters for each run was between 10 and 30, depending on the frequency and the duration. Although different number of wave cycles were considered in the analysis for each run, the data analysis procedure included peak and trough variability for each single test, expressed by 95\% confidence interval bounds of the mean value according to the sample number.

The tank is $100 \mathrm{~m}$ long, $3.55 \mathrm{~m}$ wide and the water depth was set to $1.4 \mathrm{~m}$. Test conditions were sufficient to produce slamming. To measure rapid transient pressure pulses, a sampling rate of $15 \mathrm{kHz}$ was initially used but this was reduced to $10 \mathrm{kHz}$ because of occasional buffering issues during the tests. The $10 \mathrm{kHz}$ rate, however, was deemed to be sufficient for measuring the transient slamming pulses according to previous experiments [42]. The buffering issues were possibly caused due to the limitation of the DAQ system when used in the multichannel scanning mode at a high sampling rate.

\section{Results and Discussions}

\subsection{Wet-deck slamming occurrence}

In this section, the relationship between the centre bow immersion depth and wetdeck slamming occurrence in regular waves is investigated. Similar to previous work by Lavroff and Davis [6], the approach here is to evaluate the centre bow immersion relative to the undisturbed water surface 
Figure 7(a) shows time records of the catamaran model heave, pitch, vertical bow displacement and encountered wave elevations at a reference section which is $77.6 \%$ of the overall length $(1940 \mathrm{~mm})$ from the transom, corresponding to the longitudinal location of the forward moving wave probe. The measured wave height is $89 \mathrm{~mm}$ and the dimensionless wave encounter frequency is $\omega_{\mathrm{e}}^{*}=4.04$, noting that $\omega_{e}^{*}=\omega_{e} \sqrt{\frac{L_{\mathrm{m}}}{g}}$, where $\omega_{e}$ denotes wave angular encounter frequency, $L_{\mathrm{m}}$ denotes the overall model length and $g$ denotes acceleration due to gravity.

Figure 7(b) shows time variations of the relative bow displacement to the undisturbed incident wave elevations at the reference section, followed by variations of centre bow immersion depth, top arch clearance and the total load acting on the parent centre bow. The bow immersion depth is derived by considering the undisturbed wave elevations above the keel of centre bow at the reference section. The top arch clearance is then derived by calculating the vertical distance from the bow immersion depth to the top of the archway between the demihull and the centre bow. More details can be found in [8].

The slamming instants, identified by considering the instants of peak CB loads, are shown by square markers in each subplot in Figure 7(a-b). As can be seen, slamming instants are defined by the peak CB force, and correspond closely to the instants at which the pitch (bow down) and centre bow immersion are at a maximum or when the arch top clearance is at minimum. The heave and wave elevation are out of phase at the slamming instants, heave decreasing and the wave elevation increasing. The CB peak loads show significant variation although the heave, pitch and wave elevations at the slam instants are quite similar. The variations of slam loads at a given relative velocity will be investigated in detail in Section 3.3.

Further analyses show that the increases in wet-deck and arch top heights from the parent $\mathrm{CB}$ to high $\mathrm{CB}$ do not result in slamming avoidance because the centre bow vertical displacement also increases due to increased pitch and heave motions. This is illustrated in Figure 8, which shows the amplitude of vertical bow displacement 
(normalised by the wave height) as a function of dimensionless wave encounter frequency. The error bars show the 95\% confidence interval for the normalised values, considering that the variation in non-dimensional bow vertical displacements is due to the variations in bow vertical displacements and amplitudes of waves. As can be seen, the dimensionless bow vertical displacements are larger in $60 \mathrm{~mm}$ waves compared to $90 \mathrm{~mm}$ waves. This indicates that the responses are nonlinear, which is quite typical. The amplitudes of dimensionless vertical displacement along the hull generally reduce with the increase of wave height due to the increase of local water-plane area.

In $90 \mathrm{~mm}$ waves, the range of wave encounter frequency at which slamming occurred was quite broad and similar for the three CBs tested, from $\omega_{\mathrm{e}}^{*}$ just above 3 to 7 . This corresponds to a wavelength ratio of 2.3 and smaller as shown in the second horizontal axes. In $60 \mathrm{~mm}$ waves, the high CB experienced slamming in a narrower range $\left(4<\omega_{\mathrm{e}}^{*}<5\right)$ compared to that for the parent and low CBs ( $\left.3<\omega_{\mathrm{e}}^{*}<7\right)$. It is evident that the bow motion is quite large, approaching three times the wave height. The slamming force as a function of wave encounter frequency for the parent, high and low CBs is given in [19].

The analyses of vertical displacement at slamming with respect to the undisturbed incident wave surface can be extended from the LCG to other sections to identify slamming occurrences. This is shown in Figure 9 which depicts the catamaran model and the longitudinal wave profile along its hull at arbitrary slamming instants at two wave encounter frequencies. In each subfigure, the curve labelled as "arch top" shows the highest point within the archways. The vertical distance between the wave profile and the arch top line therefore indicates the arch top clearance along the centre bow. As can be seen, the variation of the arch top clearance in the range from the centre bow truncation at $76 \%$ of the overall length up to aft jaw line point at $84 \%$ of the length is not significant.

In addition, the minimum vertical clearance between the catamaran model cross deck structure and the wave profile occurs aft of the centre bow truncation. Therefore, both the wet-deck height and an effective arch height need to be considered in the slam identification process for WPCs relative to the undisturbed 
water surface. However, the effective arch height for slamming occurrence is frequency dependent.

Figure 10 shows that overall slamming can occur when the CB immersion depth at slam is in the range between $32 \%$ and $63 \%$ of the arch height. In this and subsequent similar figures, the boxes with their central line indicate the 25th, 50th and 75th percentile values, and the whiskers show the extreme observed values, excluding outliers, which are measured values that exceed three standard deviations from the mean. This outcome is broadly consistent with the approach of Lloyd's Register rules for WPCs, which mentions that a maximum of two thirds of the arch height should be taken into account when using the design rules for slamming pressures. On the other hand, the observations by Swidan et al. [43] using high, constant vertical speed drop tests showed an immersion depth at slam just below $90 \%$ of the arch height for a bow section geometrically similar to the parent CB.

The discrepancy between the model scale tests and the drop tests for the immersion depth in which slamming occurs merits further investigations. The threedimensional effects, high forward speed, the centre bow vertical velocity and wave-centre bow interactions are probably the main factors contributing to such discrepancy because the centre bow immersion and arch filling are strongly influenced by motion responses of the catamaran model as a function of wave encounter frequency [8].

Although the water pile-up and the bow wave have significant influence on the relative motion analyses for slamming computation, the analyses regarding the undisturbed linear waves were conducted here to show the centre bow immersion at slamming instants relative to the undisturbed wave profile. Since the slamming instants were identified using the external load acting on the centre bow, they are expected to be highly correlated with the time in which the pressure builds up under the arched wet-deck to reach a maximum. The time in which the measured arch slamming pressures begin to buildup depends on the location of the pressure transducers. However, the time differences between the starting of pressure buildup and slamming instants are expected to be very small and thus the centre 
bow immersion relative to the undisturbed wave obtained at slamming instants should be similar to that at the start of pressure buildups. The information regarding the centre bow immersion at slamming can be used in design in order to minimize slamming loads and pressures and also to maximize the centre bow buoyancy which reduces the risk of deck diving. More details on slamming kinematics and centre bow design can be found in Shabani et al. [8].

\subsection{Wet-deck slamming pressures}

Sample time records of slamming pressures for the parent CB measured in $60 \mathrm{~mm}$ waves $\left(\omega_{\mathrm{e}}^{*}=4.5\right)$ at various frames (i.e. Fr72 to Fr75) for inboard, arch top and outboard locations are shown in Figure 11. As can be seen, the peak pressures are distributed within $20 \mathrm{~ms}$, with a considerable difference in magnitudes.

A wide range of variability in peak pressures was also observed across multiple slamming events in a single run. Figures 12 and 13 show the distribution of peak pressures for the high, parent and low CBs in $60 \mathrm{~mm}$ waves for $\omega_{\mathrm{e}}^{*}=4.75$ and $\omega_{\mathrm{e}}^{*}=5.6-5.7$. Each box and whisker plot shows the range of measured peak pressures during the runs at the specific location of the pressure transducer. Therefore, three box plots are shown for frames 72 to 75, presenting peak pressure variations at inboard, arch top and outboard, while a single box plot is shown for all other frames since there was only one pressure transducer located at the arch top at these frames (see Figures 3 and 5). Table 6 shows the longitudinal distances of frames with respect to the centre bow truncation and the model's transom.

As shown in Figure 12, the high CB shows only a moderate reduction in slamming pressures compared to the other CBs at $\omega_{e}^{*}=4.75$. However Figure 13 shows that slamming pressures are alleviated in the high CB configuration at the higher encounter frequency $\left(\omega_{\mathrm{e}}^{*}=5.6-5.7\right)$ since the peak pressures for the high CB are considerably lower at $\omega_{e}^{*}=5.68$ compared to peak pressures at $\omega_{e}^{*}=4.75$.

Although all CBs have lower slam pressures at the higher encounter frequencies compared to $\omega_{e}^{*}=4.75$, the reduction of slamming pressures in the parent and low CB configurations are much smaller than that seen for the high CB. In addition, the results also show that the inboard peak pressures are generally greater than arch top and outboard peak pressures. This suggests that a modification, such as 
flattening the arch geometry for inboard regions may to some degree help to further alleviate the peak slamming pressures.

As shown in Figure 12(b) in nominal 60 mm waves, the parent CB experienced the highest peak pressure of $23 \mathrm{kPa}$, occurring at Fr73 (inboard) for the test at $\omega_{e}^{*}=$ 4.75. In $90 \mathrm{~mm}$ waves the highest peak pressures were slightly greater than $30 \mathrm{kPa}$. Figure 14 shows a summary of maximum peak pressure analyses in $60 \mathrm{~mm}$ and 90 mm waves for various CB configurations. The results for the low CB in $90 \mathrm{~mm}$ waves are excluded because of some instrumentation issues affecting the limit of the measured peak pressures. The "maximum pressure" here is referred to as the highest peak pressure measured at a given wave encounter frequency.

The results show that for encounter frequencies in the range $4 \leq \omega_{e}^{*} \leq 5$, an increase of the wave height resulted in a change in the location of maximum peak pressures by only two frames (approximately $2.1 \%$ of the overall length). As can be seen the majority of high peak pressures in $60 \mathrm{~mm}$ are between Fr 72 and Fr73, for the frequency range between $\omega_{e}^{*}=4$ and 5 . In $90 \mathrm{~mm}$ waves, the high peak pressures in this frequency range (i.e. $4 \leq \omega_{e}^{*} \leq 5$ ) are located between Fr74 and Fr75. In addition, as shown in Figure 14 (a \&b) for $60 \mathrm{~mm}$ waves, some of the maximum peak pressures occurred aft of the CB truncation. However, the magnitudes of most of these maximum peak pressures are relatively small, particularly those at lower wave encounter frequency.

However, at higher frequencies the low CB did experience some slams aft of the CB truncation of around $15 \mathrm{kPa}$, which is not insignificant. The slamming aft of the centre bow can be explained by relative displacement analyses along the hull. At high frequency waves, i.e. short wavelengths, the wet-deck aft of the low centre bow was hit by incident wave crests, considering that the catamaran model's heave and pitch amplitudes were small in short wavelengths. More details of slamming kinematics and the short-wavelength impact type are given in [8].

The maximum peak pressures for the high CB were significantly smaller than that of the parent $\mathrm{CB}$ in $60 \mathrm{~mm}$ waves. The difference in maximum peak pressure between the low $\mathrm{CB}$ and parent $\mathrm{CB}$ in $60 \mathrm{~mm}$ was not generally significant except 
for one specific point in which the low CB showed a slightly greater magnitude for encounter frequency in the range $4 \leq \omega_{e}^{*} \leq 5$. Overall, as presented in Figure 14(b\&d), it is evident that the increase of wet-deck height from the parent CB to high CB resulted in the reduction of maximum slamming pressures in $60 \mathrm{~mm}$ waves but not in $90 \mathrm{~mm}$ waves.

\subsection{Wet-deck slamming loads and relative vertical velocity at slam}

The CB segment acceleration due to global motions and local vibrations was calculated from data obtained by two Brüel \& Kjær accelerometers. The acceleration signals were filtered using a 5th order low-pass Butterworth filter After evaluation of the effect of the cut-off frequency on the mean peak acceleration, a low pass Butterworth filter with $200 \mathrm{~Hz}$ cut-off frequency was applied to the raw accelerometers data. The CB acceleration then was used to calculate the $\mathrm{CB}$ inertia force that was required to determine the external force acting on the centre bow.

A similar filtering regime was also used for load cell data to maintain consistency. The effect of cut-off frequency on the mean peaks of the external force acting on the CB segment was evaluated and it was found that the mean peak force was stable for a filter range between $200 \mathrm{~Hz}$ and $300 \mathrm{~Hz}$. A cut-off frequency above $300 \mathrm{~Hz}$ resulted in a slight increase in load peaks but a noticeable increase in acceleration peaks while a cut-off frequency below $200 \mathrm{~Hz}$ caused a notable reduction in peak values for both acceleration and load signals.

Figure 15 compares the total vertical loads acting on the parent, high and low CBs as a function of dimensionless wave encounter frequency in $60 \mathrm{~mm}$ and $90 \mathrm{~mm}$ waves. The total vertical loads, comprising from slamming loads and the underlying (predominantly buoyant) CB force, are represented as a ratio of model's weight $(m g=27.12 \times 9.81)$. An overview of the slamming forces acting on the high, parent and low CBs in 60 and 90 mm waves is shown in Figure 16. An important consideration is that the CB slam forces and the underlying CB force due to centre bow immersion were disaggregated. This was achieved by applying a zero-phase low pass filter to the CB load signals [8] to obtain the underlying force and subtracting this from the total to obtain the slamming force. Refer to Figures 
17 and 18 for time records of the combined force, termed here as "CB total force". In $60 \mathrm{~mm}$ waves, the range of slamming force decreases as the wet-deck height increases, while in $90 \mathrm{~mm}$ the slam force range remains almost unchanged with respect to wet-deck height. However it is noted that in $90 \mathrm{~mm}$ waves the median slamming force for the high CB is lower than for the low and parent CBs. Increasing the wet-deck height is therefore beneficial for reducing the slam loads but the severe slamming load cases in large waves should be considered in structural design.

Figures 17 and 18 compare the time records of the parent CB total forces with the corresponding centre bow vertical velocity, vertical wave velocity and relative vertical bow velocity at the position of the forward wave probe ( $77.6 \%$ overall length) for two dimensionless encounter frequencies $\omega_{e}^{*}=4.57$ and 6.76 in 90 mm waves. Square markers show the slamming instants. The centre bow vertical velocity during bow entry reduces due to the centre bow buoyancy associated with an increase in immersion and the consequential centre bow deceleration. As can be seen, the vertical velocity of the centre bow becomes very small just before the slam and approaches zero soon after the slam. However, it is well known that the severity of slamming is more connected to relative vertical velocity rather than the absolute vertical velocity. As can be seen, the absolute vertical bow velocities at slam for both $\omega_{e}^{*}=4.57$ and $\omega_{e}^{*}=6.76$ were smaller than the vertical wave velocities at slam, and thus the wave contribution to the impact severity are higher than the motion contribution. At $\omega_{e}^{*}=4.57$, the contribution of the wave vertical velocity to the relative vertical velocity at slam was about $70 \%$, while at $\omega_{e}^{*}=$ 6.76, this was almost $100 \%$.

It is worth mentioning that the encountered wave profiles measured by the moving probes were corrected for mean level and amplitude based on the data collected by the stationary wave probe. The mean level error does not affect velocity, and phase error was negligible, but it was assumed that a reliable relative velocity, to a certain degree, was able to be derived from the measurements. More details on wave measurements are provided in Shabani et al. [8, 20]. 
The application of the centre bow relative velocity at slam for the prediction of the slamming force can be valuable when, for instance, an analytical prediction code is available for the motions, and conditions leading to slamming occurrences are embedded in it [18]. An alternate approach is to use the maximum relative velocity prior to the slam instead of the relative velocity at the slam. This method eliminates concerns about the identification of the slam instants, and provides an opportunity to find the maximum relative velocity based on the amplitude of relative vertical displacement and the wave encounter frequency. The successful implementation of either relative velocity at slam or maximum relative velocity prior to slam requires a strong correlation between the slam loads and the relative velocity. A more detailed approach for estimation of slamming loads as a function of relative velocity at slam in random waves is presented by Davis et al. [18].

Considering the time records in Figures 17 and 18, it appears that neither the maximum relative velocity prior to slam nor the relative velocity at slam can describe the variability of peak CB loads within a single run. However, since both peak CB loads and relative velocity were higher at $\omega_{e}^{*}=4.57$ than at $\omega_{e}^{*}=6.76$, a good correlation may be found when considering multiple runs at the same condition.

Since slamming takes place almost instantly, the accurate measurement of the relative velocity and the choice of reference section where this is measured can be pivotal factors. Therefore, before investigating the degree of correlation between the CB slam forces and the relative velocities at slam, it is desirable to investigate the relative velocity at different longitudinal positions along the centre bow length. The time variations of the relative velocity at different longitudinal positions can also be important, as the slamming force is a consequence of spatially distributed transient slam pressures.

Figure 19 compares the temporal and spatial variations of the relative velocity at two different wave frequencies. The longitudinal positions range from $71 \%$ to $84 \%$ of the overall length from the transom. The time variations range from $100 \mathrm{~ms}$ prior to slam until the slam instant with relative times indicated by $\Delta t$ in the figures. The slam forces selected are one of the strong slamming load cases 
observed at $\omega_{e}^{*}=4.57$ and $\omega_{e}^{*}=6.76$. The time of slamming is shown by $t_{s}$. A dashed vertical line in the inset figures shows the magnitude of the CB load at each $\Delta t$. The circle symbols show the relative vertical velocities at different longitudinal positions corresponding to the position of the CB pressure transducers. The relative velocities were calculated after extrapolation of the LCG wave profile and by numerical differentiation of the relative vertical displacement. The relative velocity that was directly obtained by using the forward wave probe is also included and is shown by the star marker and marked as "Direct" as shown in the legend of each chart. The results suggest a good correlation between the wave profile measured by the forward moving wave probe and that obtained by the linear wave theory (i.e. the extrapolation method) using the LCG wave probe because the ship vertical motion was identical in both calculations.

A comparison of the actual time of pressure build up at various locations along the parent centre bow is given in Shabani et al. [44]. It was shown that the outboard, arch top and the inboard pressure transducers peak at different times and locations but within a duration of about $20 \mathrm{~ms}$, in which the measured bow force also peaks at approximately halfway through the time interval. The actual CB immersion over this period is certainly greater than that shown in Figure 10 because actual CB immersion depth at slam to arch height ratio is expected to be close to 1 in that very short period. The relationship between the actual relative bow velocity and that presented in Figure 19 (using undisturbed wave profiles) is not known however.

As can be seen in Figure 19, the magnitude of the relative vertical velocity at $100 \mathrm{~ms}$ prior to slam increases in magnitude towards the bow for both wave frequencies. Since the centre bow at this time was at the early stage of the water entry, this scenario can be expected for the maximum relative velocity prior to slam. The maximum relative velocities were found to occur between 110 and $100 \mathrm{~ms}$ prior to slam in these cases. The magnitudes of the relative velocities at different locations decrease as times approach the slam instants for both frequencies. However, it appears that at $\omega_{e}^{*}=4.57$ the longitudinal variation of vertical relative velocity becomes smaller when $\Delta t$ approaches zero, while at $\omega_{e}^{*}=$ 
6.76 that trend transitions at around $\Delta t=-50 \mathrm{~ms}$ to the reverse situation of a lower magnitude of relative velocities near the bow.

Results provided in Figure 19 also indicate that at $\omega_{e}^{*}=4.57$ the relative velocity at slam is well represented by the relative velocity obtained at the reference section at $77.6 \%$ of the overall length because the longitudinal variation of relative velocity is insignificant at $\Delta t=0$. In the case of $\omega_{e}^{*}=6.67$, however, it seems that the reference point provides a slightly higher magnitude of relative velocity compared to the average magnitude of relative velocity within the archways extending from $76 \%$ to $84 \%$ of the overall length.

This analysis of the relationship between the slamming force, the relative velocity at slam and maximum velocity prior to slam was extended to all runs at all frequencies within test condition 2 (90 mm nominal wave height and $2.89 \mathrm{~m} / \mathrm{s}$ model speed). Results are shown in Figure 20 where relative velocities are calculated at $77.6 \%$ of overall length from transom. As can be readily seen, the relative velocities at slam have a much better correlation with slam forces compared to the maximum velocities prior to slam.

Figure 21 shows the same data as Figure 20(a), but uses different markers to illustrate how data points collected at different dimensionless wave encounter frequencies are distributed with respect to the linear model obtained from correlation analysis of the slamming force and relative velocity at slam. It appears that the linear fit over-predicts the slamming force for $\omega_{e}^{*}<4$ while it underpredicts the slam force for $\omega_{e}^{*}>6$.

In light of this, it is desirable to investigate whether the relative velocity at slam can be used effectively to develop empirical linear models that can describe the slam forces for various centre bow configurations. Figure 22 summarises the linear fits of various CB configurations in 60 and $90 \mathrm{~mm}$ waves. The correlation coefficients $(R)$ were calculated for all cases separately and it was found that except for the high and low CBs in $90 \mathrm{~mm}$ waves with $R \cong 0.50$, and the high CB in $60 \mathrm{~mm}$ with $R=0.64$, the other correlation coefficients were in the range 0.75 to 0.90 . 
The linear fits compared in Figure 22 show the effect of the wet-deck and centre bow archway clearance on the severity of slamming at a given relative velocity. The linear fit for low CB, parent CB and high CB indicate that slamming load can be about $150 \mathrm{~N}, 125 \mathrm{~N}$ and $107 \mathrm{~N}$, respectively, at a relative absolute impact velocity of $0.4 \mathrm{~m} / \mathrm{s}$, considering a forward speed of $2.89 \mathrm{~m} / \mathrm{s}$ and a wave height of $60 \mathrm{~mm}$. The difference amongst the high, parent and low CBs regarding slam loads at a given impact velocity becomes smaller as the wave height increases.

Interestingly, the slam force for a given relative velocity appears to be relatively unaffected by the wave height. The main consideration here is not the wave height, but the maximum relative velocity at slamming, which in $90 \mathrm{~mm}$ waves is almost double than that in $60 \mathrm{~mm}$ waves. The distribution of slamming loads at a given relative velocity requires more investigations on various regression models and related quintile analyses by considering factors such as wave encounter frequency as discussed earlier.

\section{Conclusions}

The effect of wet-deck height on slamming occurrence and slamming loads and pressures acting on WPCs was investigated through a systematic model test programme in regular head waves at a speed equivalent to 38 knots at full-scale. Testing consisted of three centre bow and wet-deck configurations, designated as low, parent and high CBs for a $2.5 \mathrm{~m}$ segmented catamaran model.

The slamming occurrence was analysed by considering the immersion along the centre bow relative to undistributed incident wave profiles reconstructed from wave measurement at the LCG of the catamaran model. Slamming instants were identified by considering the peak slamming forces. The results indicated that slamming occurs when the centre bow immersion depth relative to undisturbed wave profiles is in the range between 0.33 and 0.66 of the maximum arch height, and the wet-deck clearance at the centre bow truncation is at minimum.

The maximum peak pressures for the low, parent and high CBs were almost in the same range in $90 \mathrm{~mm}$ waves but the high CB showed a considerable reduction in 
slamming pressures compared to the parent $\mathrm{CB}$ in $60 \mathrm{~mm}$ waves. A similar trend was seen for slamming forces. The difference between the parent CB and low CB in maximum slamming pressure was not generally significant in $60 \mathrm{~mm}$ waves, but the range and median of slamming loads increased with the decrease of the wetdeck height. The highest slam pressures were observed in the range of $4<\omega_{\mathrm{e}}^{*}<$ 5. The maximum peak pressures in $60 \mathrm{~mm}$ waves were located in the protected area of the centre bow between $3.5 \%$ and $7 \%$ of the CB length from CB truncated section, or approximately $77 \%$ and $78 \%$ of the overall length from the transom. An increase of the wave height resulted in significant increases for both peak slamming pressures and loads while the location of maximum peak pressures was also displaced forward by about $2 \%$ of the overall length.

The relationship between the centre bow relative velocity and the severity of slam loads was investigated to determine the influence wet-deck height on the slam load-relative velocity relationship. This suggested that, in regular waves, linear regressions can be used for determination of slamming severity based on the relative velocity at impact obtained from motion analyses. However, the variation of slamming loads at a given relative velocity should be considered using multivariable regression.

The results of current investigation support the consideration of the effective air gap for arch top clearance as described in Lloyds's Register SSC rules. However, further investigation is recommended for the evaluation of experimental slamming pressures in comparison with class rules. Since the scale factor (1:44.8) in this study was quite small, further investigation on the effect of air entrapment within the archways and during the slamming is recommended as the measured pressures could be affected by detail of the converging jets inside the archways. In addition, the centre bow effect on design loads and pressures has not been formulated in the rules provided by the class societies, and therefore more effort may be required in this area. More broadly, further investigation is recommended to identify the relationship between slam pressures at full-scale to that in the model test experiments. 
The results presented in this paper do not consider the influence of the centre bow entry on wave elevation and use the undisturbed wave profile measurement in regular waves. More investigations are recommended in irregular waves using various centre bow configurations. In addition, all tests have been conducted in head seas and it would be of interest to undertake future model tests in oblique wave headings. It would also be of the interest to perform a series of tests for an equivalent flat wet-deck Incat catamaran to define more clearly the role of the centre bow in improving the seakeeping characteristics of a large wave piercing catamaran.

\section{Acknowledgements}

This work was undertaken in collaboration between the University of Tasmania, Revolution Design and International Catamarans Tasmania (INCAT) through the support of the Australian Research Council Linkage Grant number LP0883540. The work of Dr Jalal Rafie Shahraki in the development and production of the hydroelastic segmented model is also gratefully acknowledged.

\section{References}

[1] Fang C-C, Chan H-S. An investigation on the vertical motion sickness characteristics of a high-speed catamaran ferry. Ocean Engineering. 2007;34:190917.

[2] Boulton C. The AMD wavepiercing catamaran-Seakeeping Excellence Proceedings of the 14 th Fast Ferry International Conference. Bells Center, Copenhagen: Fast Ferry International Ltd.; 1998. p. 24-6.

[3] Dubrovsky VA. Application and Development of Multi-Hulls. Journal of Ocean, Mechanical and Aerospace -Science and Engineering. 2014;6:1-7. [4] Soars A. The Hydrodynamic Development of Large Wave Piercing Catamarans. 9th International High Speed Surface Craft Conference. Singapore: High Speed Surface Craft Associates; 1993.

[5] Lavroff J, Davis MR, Holloway DS, Thomas GA, McVicar JJ. Wave impact loads on wave-piercing catamarans. Ocean Engineering. 2017;131:263-71. 
[6] Lavroff J, Davis MR. Slamming kinematics, impulse and energy transfer for wave-piercing catamarans. Journal of Ship Research. 2015;59:145-61.

[7] Lavroff J, Davis MR, Holloway DS, Thomas G. Wave slamming loads on wave-piercer catamarans operating at high-speed determined by hydro-elastic segmented model experiments. Marine Structures. 2013;33:120-42.

[8] Shabani B, Lavroff J, Davis MR, Holloway DS, Thomas GA. Slam loads and kinematics of wave-piercing catamarans during bow entry events in head seas. Journal of Ship Research. 2018; 62(3):134-55.

[9] Thomas G, Winkler S, Davis M, Holloway D, Matsubara S, Lavroff J, et al. Slam events of high-speed catamarans in irregular waves. Journal of Marine Science and Technology. 2011;16:8-21.

[10] Thomas GA, Davis MR, Holloway DS. The whipping vibration of large high speed catamarans. International Journal of Maritime Technology. 2003;145:289304.

[11] Lloyd'sRegister. Rules and Regulations for the Classification of Special Service Craft. Lloyd's Register: London: Lloyd's Register Group Services Limited; 2017.

[12] DNV-GL. DNV GL rules for classification: High speed and light craft (RUHSLC). 2015-12 ed: Det Norske Veritas \& Germanischer Lloyd 2015.

[13] Ochi MK. Prediction of occurrence and severity of ship slamming at sea. Fifth symposium of naval hydrodynamics. Bergen, Norway: Office of Naval Research; 1964. p. 545-96.

[14] Dessi D, Ciappi E. Slamming clustering on fast ships: From impact dynamics to global response analysis. Ocean Engineering. 2013;62:110-22.

[15] Ochi MK, Motter LE. Prediction of slamming characteristics and hull responses for ship design. Transaction of The Society of Naval Architecture and Marine Engineering. 1973; 81:144-76.

[16] Davis MR, Holloway DS, Watson NL. Comparison of measured and computed non-linear wave loads using a time domain method for an $86 \mathrm{~m}$ catamaran. Australian Journal of Mechanical Engineering. 2006;3:143-54. [17] French BJ. Slamming of large high-speed catamarans in irregular seas: $\mathrm{PhD}$ Thesis, University of Tasmania; 2012. 
[18] Davis MR, French BJ, Thomas GA. Wave slam on wave piercing catamarans in random head seas. Ocean Engineering. 2017;135:84-97.

[19] Shabani, B., Lavroff, J., Holloway, D.S., Davis, M.R. and Thomas, G.A., 2018. The effect of centre bow and wet-deck geometry on wet-deck slamming loads and vertical bending moments of wave-piercing catamarans. Ocean Engineering, 169, pp.401-417.

[20] Shabani B, Lavroff J, Holloway DS, Davis MR, Thomas GA. The influence of the centre bow and wet-deck geometry on motions of wave-piercing catamarans. Proceedings of the Institution of Mechanical Engineers, Part M: Journal of Engineering for the Maritime Environment. 2018.

[21] Kapsenberg GK. Slamming of ships: where are we now? Philosophical transactions Series A, Mathematical, physical, and engineering sciences. 2011;369:2892-919.

[22] Temarel P, Bai W, Bruns A, Derbanne Q, Dessi D, Dhavalikar S, et al. Prediction of wave-induced loads on ships: Progress and challenges. Ocean Engineering. 2016;119:274-308.

[23] Wang S, Soares CG. Review of ship slamming loads and responses. Journal of Marine Science and Application. 2017;16:427-45.

[24] Dias F, Ghidaglia J-M. Slamming: Recent progress in the evaluation of impact pressures. Annual Review of Fluid Mechanics. 2018;50:243-73.

[25] Zhao R, Faltinsen O. Water entry of two-dimensional bodies. Journal of Fluid Mechanics. 1993;246:593-612.

[26] Faltinsen O, Chezhian M. A generalized Wagner method for threedimensional slamming. Journal of ship research. 2005;49:279-87.

[27] Dessi D, Faiella E, Geiser J, Alley E, Dukes J. Design and structural testing of a physical model for wetdeck slamming analysis. 2017.

[28] Farsi M, Ghadimi P. Effect of flat deck on catamaran water entry through smoothed particle hydrodynamics. Proceedings of the Institution of Mechanical Engineers, Part M: Journal of Engineering for the Maritime Environment. 2016;230:267-80.

[29] Dubrovsky VA. Multi-hulls: Slamming, Upper Deck Wetness and Dimension Selection. Journal of Traffic and Transportation Engineering. 2015;3:289-92. 
[30] AlaviMehr J, Lavroff J, Davis MR, Holloway DS, Thomas GA. An experimental investigation of ride control algorithms for high-speed catamarans Part 2: Mitigation of wave impact loads. Journal of Ship Research. 2017;61:51-63. [31] McVicar JJ, Lavroff J, Davis MR, Thomas G. Effect of slam force duration on the vibratory response of a lightweight high-speed wave-piercing catamaran. Journal of Ship Research. 2015;59:69-84.

[32] Swidan A, Thomas G, Penesis I, Ranmuthugala D, Amin W, Allen T, et al. Wetdeck slamming loads on a developed catamaran hullform - experimental investigation. Ships and Offshore Structures. 2016;12:653-61.

[33] Shahraki J, Thomas G, Davis M. The Influence of Centre Bow Length On Slamming Loads and Motions of Large Wave-piercing Catamarans. Transactions of the Royal Institution of Naval Architects Part A: International Journal of Maritime Engineering. 2018;160.

[34] McVicar J, Lavroff J, Davis MR, Thomas G. Fluid-structure interaction simulation of slam-induced bending in large high-speed wave-piercing catamarans. Journal of Fluids and Structures. 2018;82:35-58.

[35] Abdul Ghani P, Wilson P. Experimental analysis of the seakeeping performance of catamaran forms with bulbous bows. International Shipbuilding Progress. 2017:1-29.

[36] Davis MR, Holloway DS. Motion and passenger discomfort on high speed catamarans in oblique seas. International shipbuilding progress. 2003;50:333-70. [37] Lavroff J, Davis MR, Holloway DS, Thomas G. Determination of wave slamming loads on high-speed catamarans by hydroelastic segmented model experiments. International Journal of Maritime Engineering. 2011;153:185-97. [38] Lavroff J, Davis MR, Holloway DS, Thomas GA. The Vibratory Response of High-Speed Catamarans to Slamming Investigated by Hydroelastic Segmented Model Experiments. International Journal of Maritime Engineering. 2009;151:113.

[39] Shahraki JR, Thomas G, Penesis I, Amin W, Davis M, Davidson G.

Centrebow design for wave-piercing catamrans. FAST 2013-12th International Conference on Fast Sea Transportation2013. 
[40] Lavroff J. The Slamming and Whipping Vibratory Response of a Hydroelastic Segmented Catamaran Model: PhD Thesis, University of Tasmania; 2009.

[41] Rafie Shahraki J. The influence of hull form on the slamming behaviour of large high speed catamarans: PhD Thesis, University of Tasmania; 2014.

[42] Amin W. Non-linear unsteady wave loads on large high-speed wave piercing catamarans: PhD Thesis, University of Tasmania; 2009.

[43] Swidan A, Thomas G, Ranmuthugala D, Amin W, Penesis I, Allen T, et al. Experimental drop test investigation into wetdeck slamming loads on a generic catamaran hullform. Ocean Engineering. 2016;117:143-53.

[44] Shabani, B., Lavroff, J., Davis, M.R., Holloway, D.S. and Thomas, G.A., 2019. Slam loads and pressures acting on high-speed wave-piercing catamarans in regular waves. Marine Structures, 66, pp.136-153. 
Table 1 Specifications of the model and full-scale catamaran vessel

\begin{tabular}{lll}
\hline Description & Model & Full scale \\
\hline Overall length & $2.5 \mathrm{~m}$ & $112.6 \mathrm{~m}$ \\
Water line length & $2.36 \mathrm{~m}$ & $105.6 \mathrm{~m}$ \\
Displacement & $27.12 \mathrm{~kg}$ & 2500 tonnes \\
Overall beam & $0.68 \mathrm{~m}$ & $30.5 \mathrm{~m}$ \\
Beam of demi-hulls & $0.13 \mathrm{~m}$ & $5.8 \mathrm{~m}$ \\
LCG (from transom) & $0.941 \mathrm{~m}$ & $42.15 \mathrm{~m}$ \\
Pitch radius of gyration & $0.69 \mathrm{~m}$ & $30.91 \mathrm{~m}$ \\
\hline
\end{tabular}


Table 2 Instruments used in catamaran model tests in regular waves

\begin{tabular}{lll}
\hline Sensors & Quantity & Description \\
\hline Pressure transducers (PT) & 18 & $\begin{array}{l}\text { 8510C Endevco piezoresistive pressure } \\
\text { transducers }\end{array}$ \\
Load cells (LC) & 2 & Mini 45 ATI force/moment transducers \\
Accelerometer (A) & 2 & $\begin{array}{l}\text { Brüel \& Kjær accelerometers (Type 4370 } \\
\text { \& 4371) }\end{array}$ \\
LVDT & 2 & Linear variable differential transformers \\
Stationary wave probe & 1 & Resistive type \\
Moving wave probe & 2 & Resistive type \\
\hline
\end{tabular}


Table 3 Main characteristics of various centre bow and wet-deck configurations

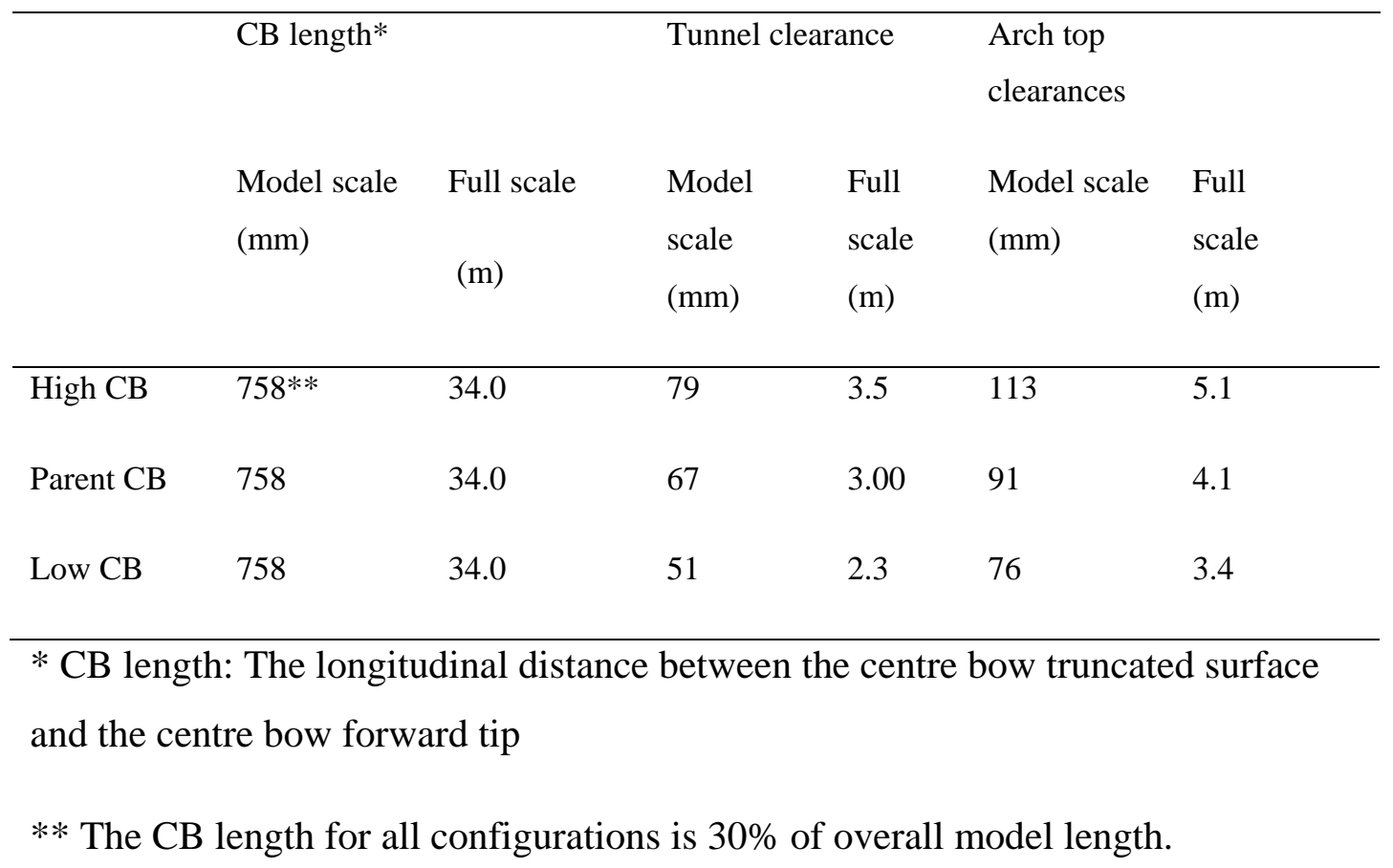




\section{Table 4 Model test conditions}

Model scale Full-scale

\begin{tabular}{|c|c|c|c|c|c|}
\hline & Centre bow & Velocity & $\begin{array}{l}\text { Wave } \\
\text { height }\end{array}$ & $\begin{array}{l}\text { Velocity } \\
\text { (knots) }\end{array}$ & $\begin{array}{l}\text { Wave } \\
\text { height }\end{array}$ \\
\hline & & $\begin{array}{l}V_{m} \\
(\mathrm{~m} / \mathrm{s})\end{array}$ & $h_{w}(\mathrm{~mm})$ & $V_{s}$ (knots) & $H(\mathrm{~m})$ \\
\hline $\begin{array}{l}\text { Condition } \\
1\end{array}$ & $\begin{array}{l}\text { high, parent and } \\
\text { low CBs }\end{array}$ & 2.89 & 60 & 38 & 2.7 \\
\hline $\begin{array}{l}\text { Condition } \\
2\end{array}$ & $\begin{array}{l}\text { high, parent and } \\
\text { low CBs }\end{array}$ & 2.89 & 90 & 38 & 4.0 \\
\hline
\end{tabular}


Table 5 Number of runs, wave frequencies and wave statistics for each centre bow tank test.

\begin{tabular}{|c|c|c|c|c|c|}
\hline $\begin{array}{l}\text { Centr } \\
\text { e bow }\end{array}$ & $\begin{array}{l}\text { Numbe } \\
\text { r of } \\
\text { runs }\end{array}$ & Wave frequencies $(\mathrm{Hz})$ & $\begin{array}{l}\text { Nomina } \\
\text { l wave } \\
\text { height } \\
(\mathrm{mm})\end{array}$ & $\begin{array}{l}\text { Wave } \\
\text { heigh } \\
\mathrm{t} \\
\text { mean } \\
\mu_{\bar{h}_{w}}, \\
(\mathrm{~mm})\end{array}$ & $\begin{array}{l}\text { Wave height } \\
\text { standard } \\
\text { deviation, } \\
\sigma_{\bar{h}_{w}}(\mathrm{~mm})\end{array}$ \\
\hline $\begin{array}{l}\text { High } \\
\text { CB }\end{array}$ & 12 & $\begin{array}{l}0.55,0.6,0.64,0.67,0.7,0.73, \\
0.73,0.75,0.77,0.8,0.84,0.88\end{array}$ & 60 & 61.37 & 1.07 \\
\hline $\begin{array}{l}\text { Parent } \\
\text { CB }\end{array}$ & 26 & $\begin{array}{l}0.43,0.45,0.48,0.51,0.53,0.55 \\
0.55,0.58,0.58,0.58,0.58 \\
0.6,0.61,0.63,0.65,0.67,0.7 \\
, 0.7,0.7,0.72,0.74,0.77,0.8,0.82,0.84,0.87\end{array}$ & 60 & 57.06 & 2.82 \\
\hline $\begin{array}{l}\text { Low } \\
\text { CB }\end{array}$ & 15 & $\begin{array}{l}\text { 0.36,0.4,0.45,0.49,0.53,0.54,0.6,0.62, } \\
0.65,0.67,0.7,0.73,0.75,0.8,0.9\end{array}$ & 60 & 59.13 & 1.91 \\
\hline $\begin{array}{l}\text { High } \\
\text { CB }\end{array}$ & 10 & $\begin{array}{l}0.5,0.55,0.6,0.64,0.67,0.7,0.73,0.75,0.77,0 . \\
8\end{array}$ & 90 & 91.80 & 1.73 \\
\hline $\begin{array}{l}\text { Parent } \\
\text { CB }\end{array}$ & 22 & $\begin{array}{l}\text { 0.42,0.44,0.47,0.5,0.52,0.55,0.55,0.55, } \\
\text { 0.57,0.6,0.62,0.65,0.65,0.65,0.65,0.67, } \\
0.7,0.73,0.75,0.77,0.8,0.84\end{array}$ & 90 & 88.52 & 4.16 \\
\hline $\begin{array}{l}\text { Low } \\
\text { CB }\end{array}$ & 16 & $\begin{array}{l}0.36,0.39,0.45,0.5,0.53,0.55,0.57 \\
0.6,0.63,0.65,0.67,0.7,0.73,0.75,0.8,0.9\end{array}$ & 90 & 90.23 & 2.77 \\
\hline
\end{tabular}


Table 6 The locations of frames with respect to the centre bow truncation and the model's transom

\begin{tabular}{lllllllllll}
\hline Frame Number & 66 & 68 & 70 & 72 & 73 & 74 & 75 & 76 & 77 & 78 \\
\hline $\begin{array}{l}\text { Longitudinal distance } \\
\text { from the centre bow truncation } \\
\text { ( \% of the overall length) }\end{array}$ & -5.7 & -3.5 & -1.4 & 0.7 & 1.8 & 2.9 & 3.9 & 5.0 & 6.1 & 7.1 \\
$\begin{array}{l}\text { Longitudinal distance } \\
\text { from the transom } \\
\text { (\% of the overall length) }\end{array}$ & 70.2 & 72.3 & 74.4 & 76.6 & 77.6 & 78.7 & 79.8 & 80.8 & 81.9 & 83.0 \\
\hline $\begin{array}{l}\% \\
\text { Positive (forward), Negative (aft) }\end{array}$
\end{tabular}


Figure 1 A 112 m Incat wave piercing catamaran (http://www.incat.com.au/).

Figure 2 The $2.5 \mathrm{~m}$ catamaran model (HSM02) of the 112-m INCAT wave piercing catamaran.

Figure 3 Schematic plan view of the $2.5 \mathrm{~m}$ segmented catamaran model including the forward, aft and middle segments and the locations of sensors used for instrumentation. * LVDT: linear variable differential transformers, PT: Pressure Transducers, LC: Load Cells, A: Accelerometers.

Figure 4 (a) Schematic representation of a centre bow and wet-configuration, showing the flat wet-deck position, arch top clearance, arch top height (b) Sectional representation at longitudinal position $1892 \mathrm{~mm}$ relative to the transom for the HSM02 model with the high, parent and low CBs

Figure 5 Locations of the outboard, top arch and inboard pressure transducers for the parent CB.

Figure 6 Vertical locations (z) of the pressure transducers for different CB configurations, normalised by the draft (T) at DWL.

Figure 7 HSM02 catamaran (parent CB) model motions and centre bow immersion synchronised with slam loads in $\boldsymbol{h}_{\boldsymbol{w}}=\mathbf{9 0} \mathrm{mm}, \boldsymbol{V}_{\boldsymbol{m}}=\mathbf{2 . 8 9} \mathrm{m} / \mathrm{s}$ and $\boldsymbol{\omega}_{\boldsymbol{e}}^{*}=\mathbf{4 . 0 4}$. The squares and vertical dashed lines show the values at slam instants. The reference section is at $77.6 \%$ of overall length $(1940 \mathrm{~mm})$ from transom, corresponding to the longitudinal location of the forward moving wave probe. (a) Time records of heave, pitch, encountered wave elevation and bow vertical displacement (b) Time records of relative bow displacement, centre bow immersion depth, arch top clearance and vertical loads acting on the centre bow

Figure 8 Dimensionless bow vertical displacement of the catamaran model with different bow and wet-deck configurations at a speed of $2.89 \mathrm{~m} / \mathrm{s}$ in two wave heights: (a) $60 \mathrm{~mm}$ and (b) $90 \mathrm{~mm}$.

Figure 9 Vertical model displacement and encountered wave profile at slamming instants for the catamaran model with the parent CB in $\boldsymbol{h}_{\boldsymbol{w}}=\mathbf{9 0} \mathrm{mm}, \boldsymbol{V}_{\boldsymbol{m}}=\mathbf{2 . 8 9} \mathrm{m} / \mathrm{s}$ (a) $\boldsymbol{\omega}_{\boldsymbol{e}}^{*}=$ 4.57 (b) $\omega_{e}^{*}=6.76$. 
Figure 10 Box plot presentations of CB immersion depth at slam to arch height ratio, considering multiple wave encounter frequencies at each test conditions. The red dots show the outliers.

Figure 11 Sample time records of slam pressure at various arch locations (arch top, outboard, inboard) obtained for the parent CB configuration in $60 \mathrm{~mm}$ waves at $2.89 \mathrm{~m} / \mathrm{s}$ model speed for dimensionless wave encounter frequency of $\boldsymbol{\omega}_{\boldsymbol{e}}^{*}=\mathbf{4 . 5}$ (a) Fr72 (b) Fr73 (c) Fr74 (d) Fr75. Refer to Figure 6 or 14 for more details about the frame (Fr) locations.

Figure 12 Sample peak pressures obtained for different CB configurations in $60 \mathrm{~mm}$ waves at $2.89 \mathrm{~m} / \mathrm{s}$ model speed for dimensionless wave encounter frequency of $\boldsymbol{\omega}_{\boldsymbol{e}}^{*}=$ 4. 75. (a) High CB, (b) Parent CB, (c) Low CB. Refer to Figure 6 or 14 for more details about the frame (Fr) locations.

Figure 13 Sample peak pressures obtained for different CB configurations in $60 \mathrm{~mm}$ waves at $2.89 \mathrm{~m} / \mathrm{s}$ model speed for dimensionless wave encounter frequency of $\boldsymbol{\omega}_{\boldsymbol{e}}^{*}=$ 4. 75. (a) High CB, (b) Parent CB, (c) Low CB. Refer to Figure 6 or 14 for more details about the frame $(\mathrm{Fr})$ locations.

Figure 14 The location and magnitude of maximum peak pressures as a function of wave encounter frequency for various wet-deck and centre bow configurations; (a \& b) the results in $60 \mathrm{~mm}$ waves for the low, parent and high CBs; (c \& d) the results in $90 \mathrm{~mm}$ waves for the parent and high CBs. Fr 66 to 78 show the frame locations.

Figure 15 Dimensionless vertical forces acting on the centre bow segment of HSM02 catamaran model with different centre bows and wet-deck configurations at a speed of $2.89 \mathrm{~m} / \mathrm{s}$ in 60 and $90 \mathrm{~mm}$ waves.

Figure 16 The distribution of vertical slamming forces identified for each CB in (a) $\boldsymbol{h}_{\boldsymbol{w}}=$ $60 \mathrm{~mm}$ (b) $\boldsymbol{h}_{\boldsymbol{w}}=\mathbf{9 0} \mathrm{mm}$.

Figure 17 Vertical bow, wave and relative bow velocity for the parent CB in $\boldsymbol{h}_{\boldsymbol{w}}=$

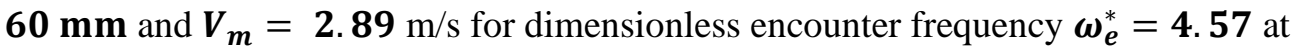
$77.6 \%$ of overall length (equivalent to $1940 \mathrm{~mm}$ ) from transom, corresponding to the longitudinal location of the forward moving wave probe.

Figure 18 Vertical bow, wave and relative bow velocity for the parent CB in $\boldsymbol{h}_{\boldsymbol{w}}=$ $90 \mathbf{m m}$ and $\boldsymbol{V}_{\boldsymbol{m}}=\mathbf{2 . 8 9} \mathrm{m} / \mathrm{s}$ for dimensionless encounter frequency $\boldsymbol{\omega}_{\boldsymbol{e}}^{*}=\mathbf{6 . 7 6}$ at 
$77.6 \%$ of overall length (equivalent to $1940 \mathrm{~mm}$ ) from transom, corresponding to the longitudinal location of the forward moving wave probe.

Figure 19 Relative bow velocity at different longitudinal positions along the centre bow at $100 \mathrm{~ms}, 50 \mathrm{~ms}$ and $25 \mathrm{~ms}$ prior to a slam and at the slamming instant for the parent CB in $\boldsymbol{h}_{\boldsymbol{w}}=\mathbf{9 0} \mathbf{\mathrm { mm }}$ and $\boldsymbol{V}_{\boldsymbol{m}}=\mathbf{2 . 8 9} \mathrm{m} / \mathrm{s}$ for dimensionless encounter frequencies $\boldsymbol{\omega}_{\boldsymbol{e}}^{*}=$ 4, 57 (left) and 6.76 (right).

Figure 20 The correlation between slam force and (a) relative velocity at slam (b) maximum relative velocity to slam for the parent CB in $\boldsymbol{h}_{\boldsymbol{w}}=\mathbf{9 0} \mathbf{m m}$ and $\boldsymbol{V}_{\boldsymbol{m}}=\mathbf{2 . 8 9}$ $\mathrm{m} / \mathrm{s}$.

Figure 21 Distribution of experimental data points categorised into four intervals of dimensionless wave encounter frequency: $\boldsymbol{\omega}_{\boldsymbol{e}}^{*}<\mathbf{4 , 4} \leq \boldsymbol{\omega}_{\boldsymbol{e}}^{*}<\mathbf{5 , 5} \leq \boldsymbol{\omega}_{\boldsymbol{e}}^{*}<\mathbf{6}, \boldsymbol{\omega}_{\boldsymbol{e}}^{*} \geq \mathbf{6}$, with respect to the linear fit obtained for slam force and relative velocity at slam for the parent CB in $\boldsymbol{h}_{\boldsymbol{w}}=\mathbf{9 0} \mathbf{~} \mathbf{m}$ and $\boldsymbol{V}_{\boldsymbol{m}}=\mathbf{2 . 8 9} \mathrm{m} / \mathrm{s}$.

Figure 22 Comparison of the linear fits describing slam force as a function of relative velocity at slam for different centre bow lengths and wet-deck configurations in $\boldsymbol{h}_{\boldsymbol{w}}=$ $60 \mathrm{~mm}$ and $V_{m}=2.89 \mathrm{~m} / \mathrm{s}$ and $\boldsymbol{h}_{\boldsymbol{w}}=90 \mathrm{~mm}$ and $\boldsymbol{V}_{\boldsymbol{m}}=2.89 \mathrm{~m} / \mathrm{s}$. 


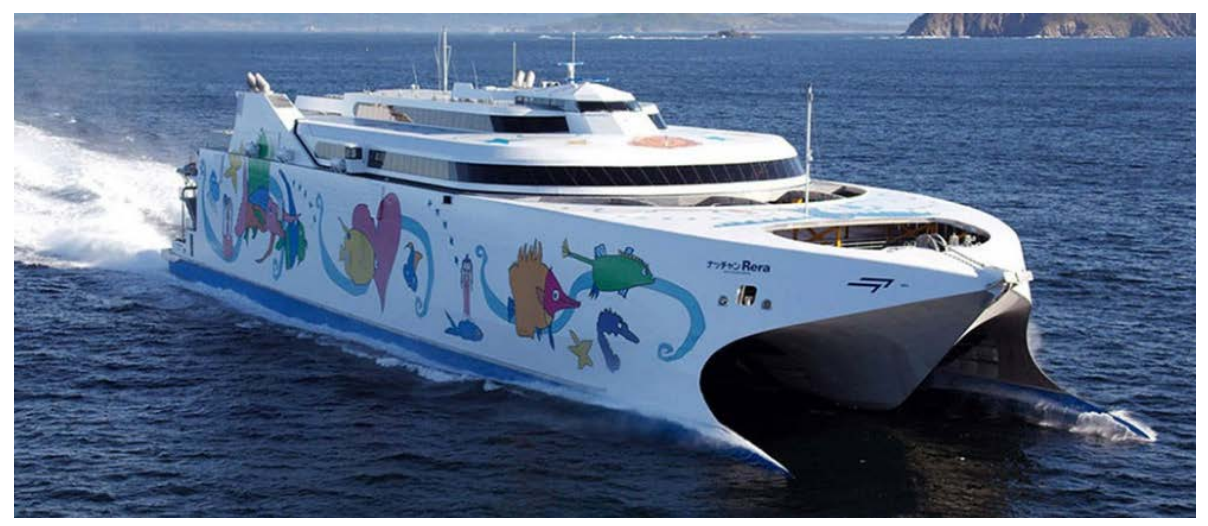

Figure 1 


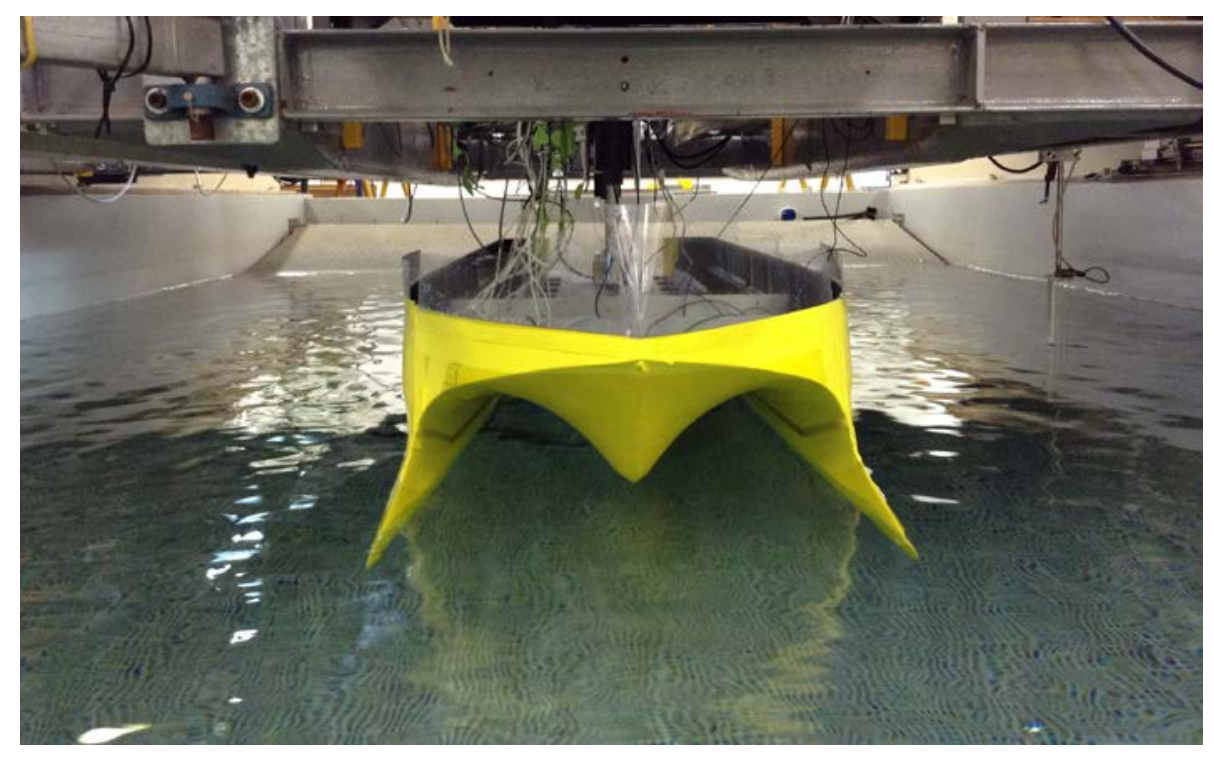

Figure 2 


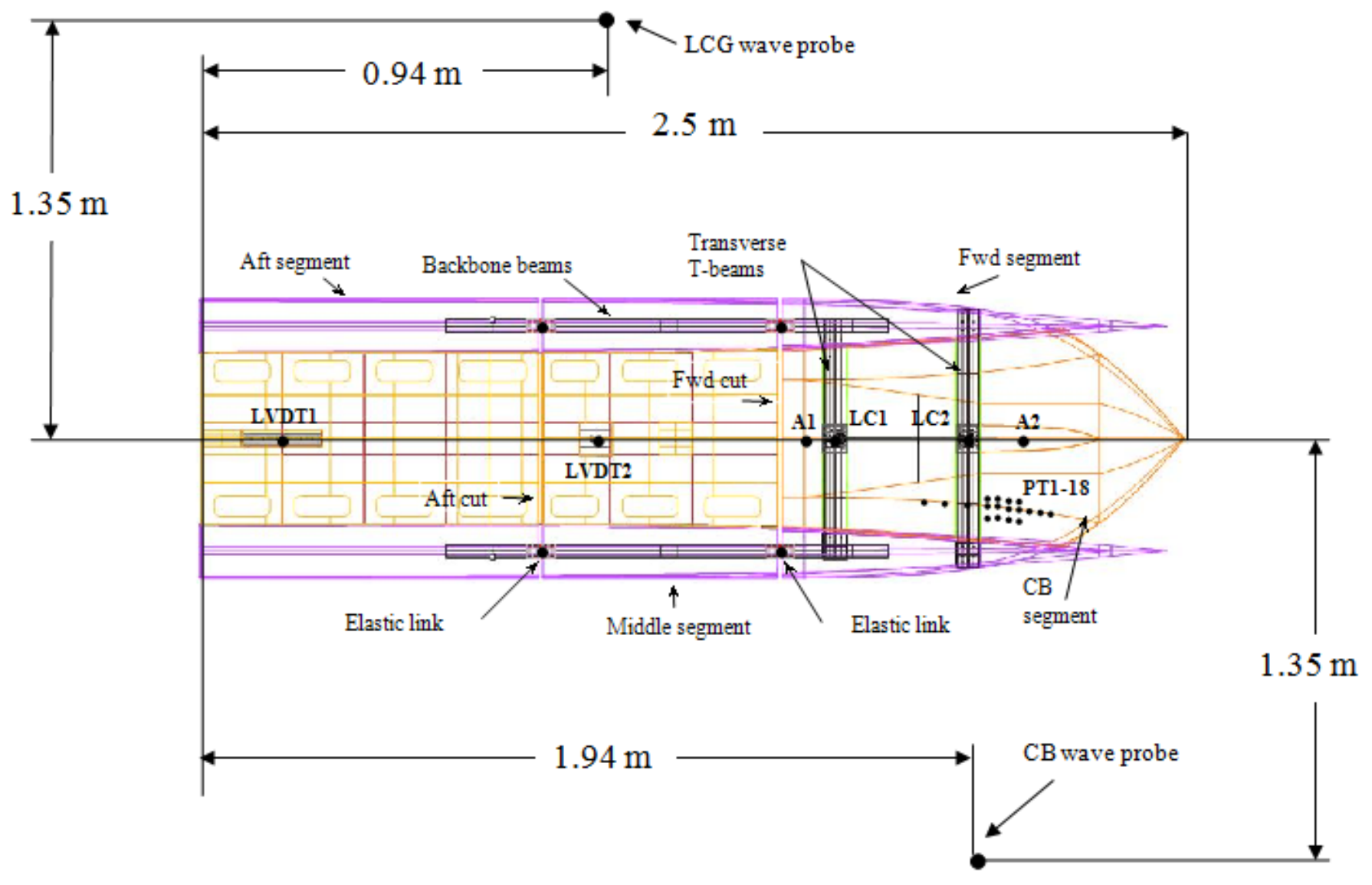

Figure 3 


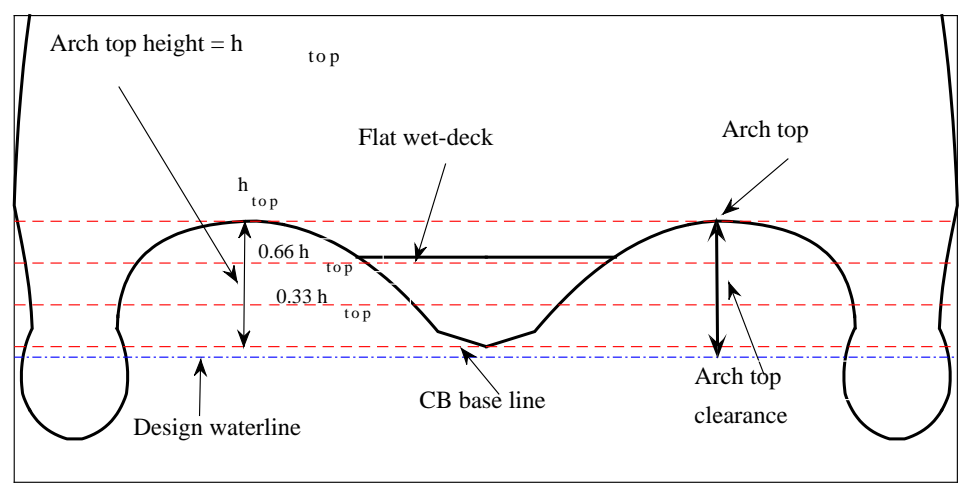

(a)

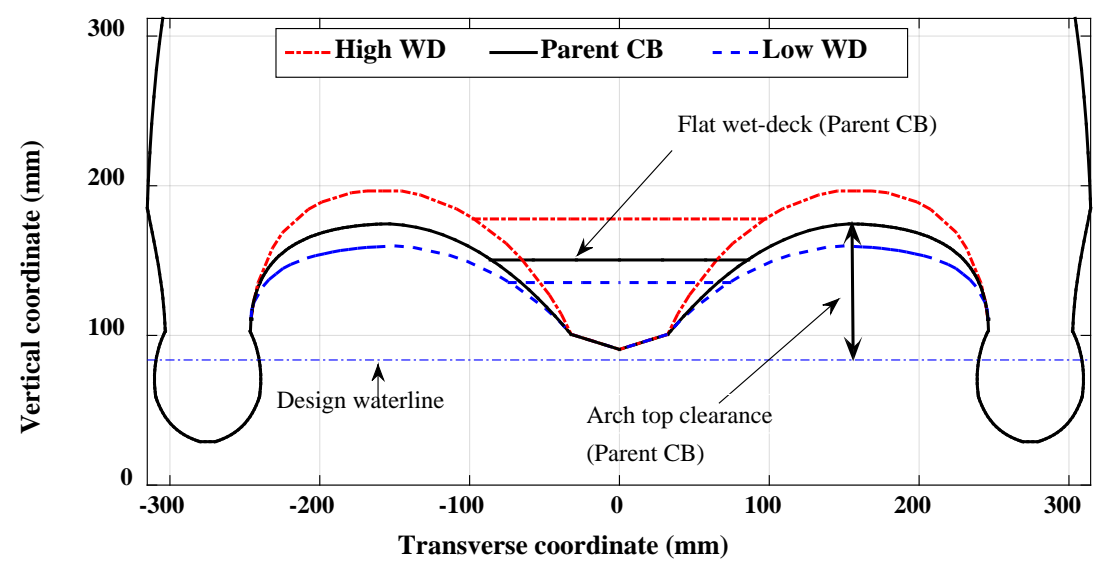

(b)

Figure 4 


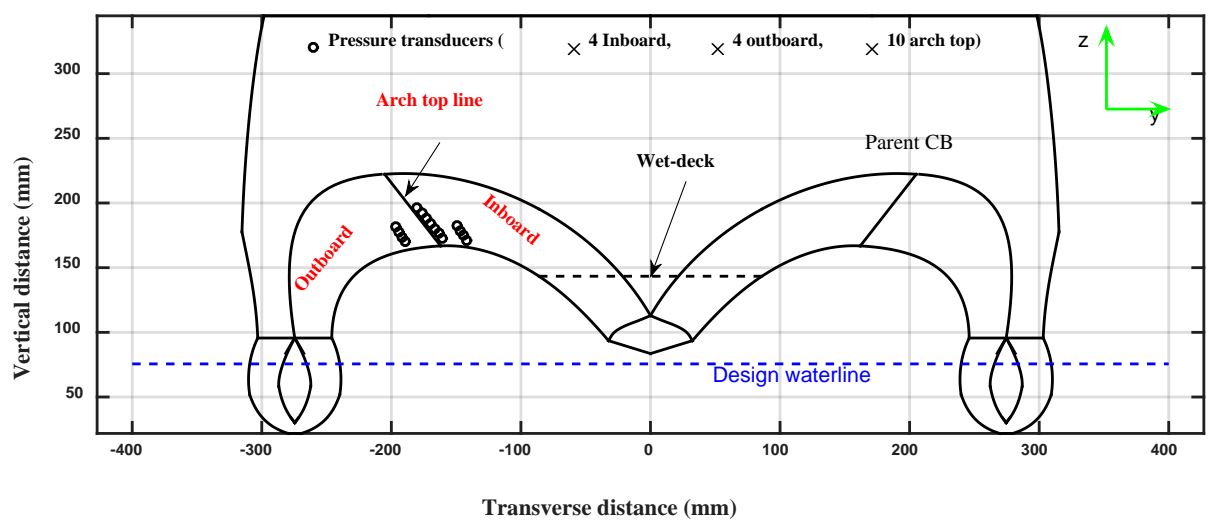

Figure 5 


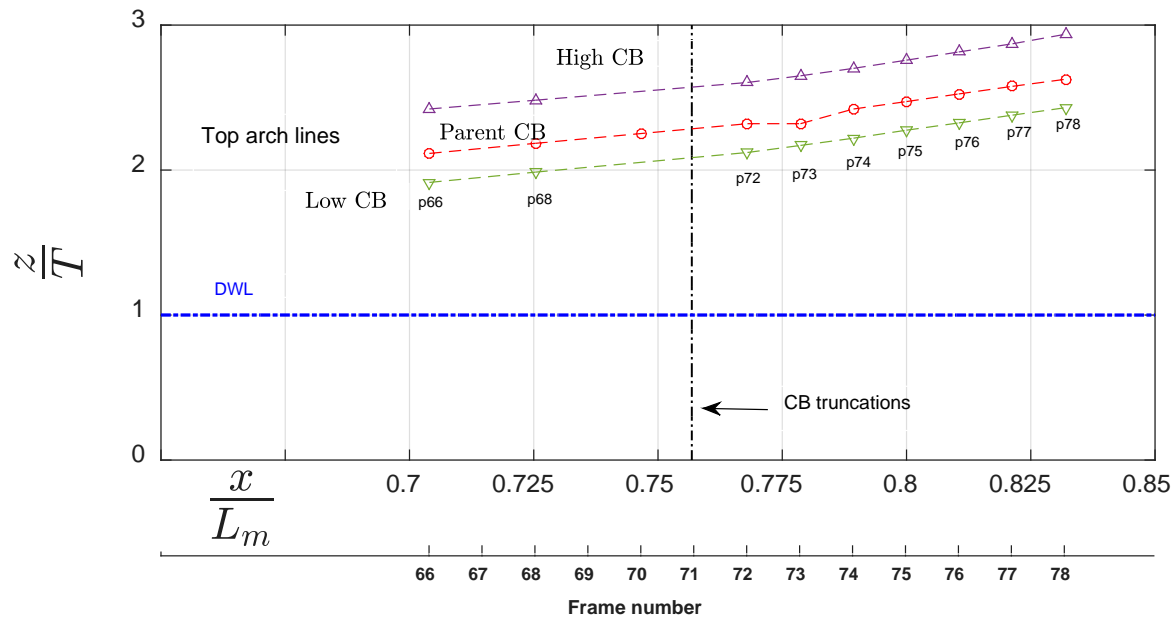

Figure 6 


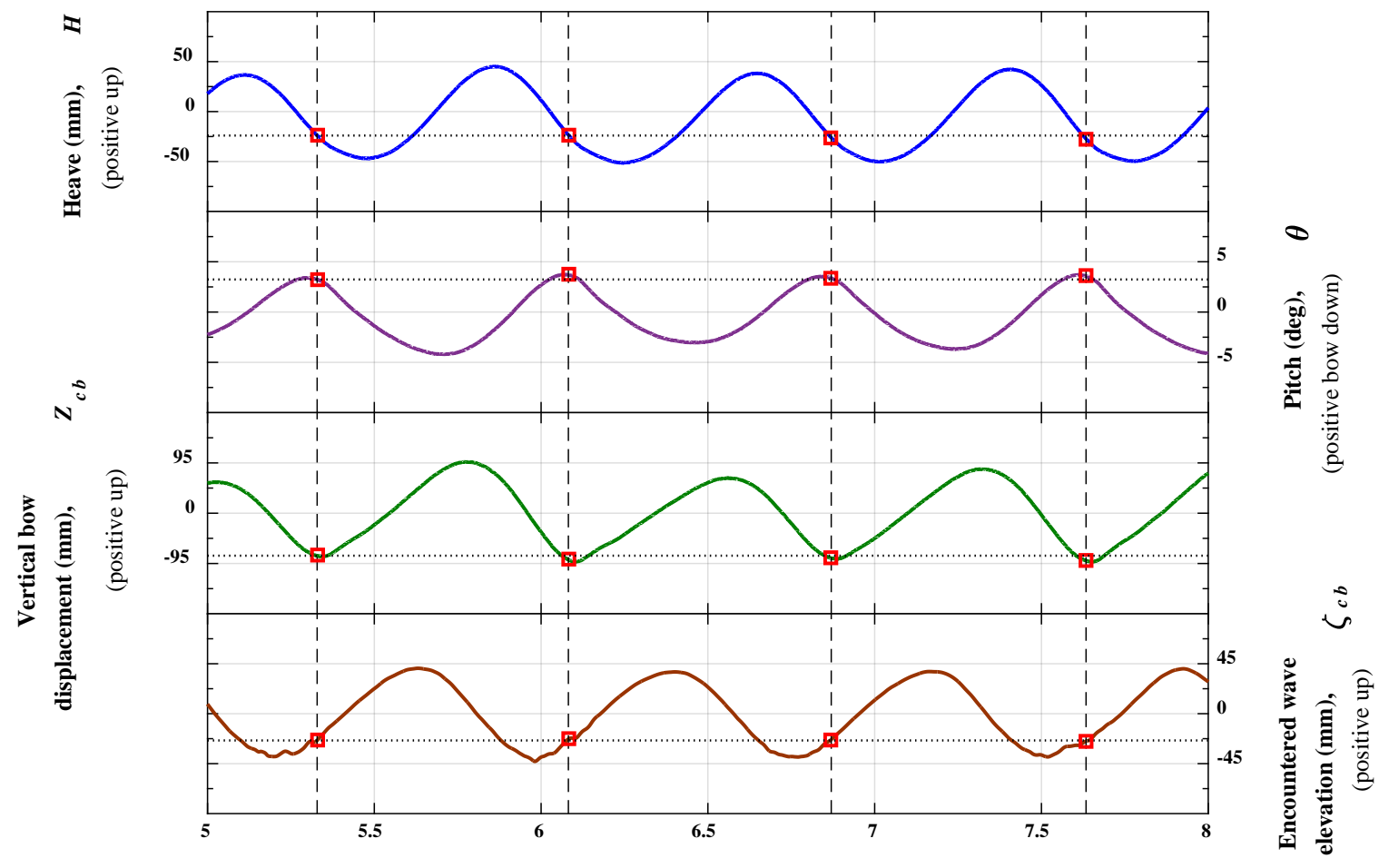

(a)

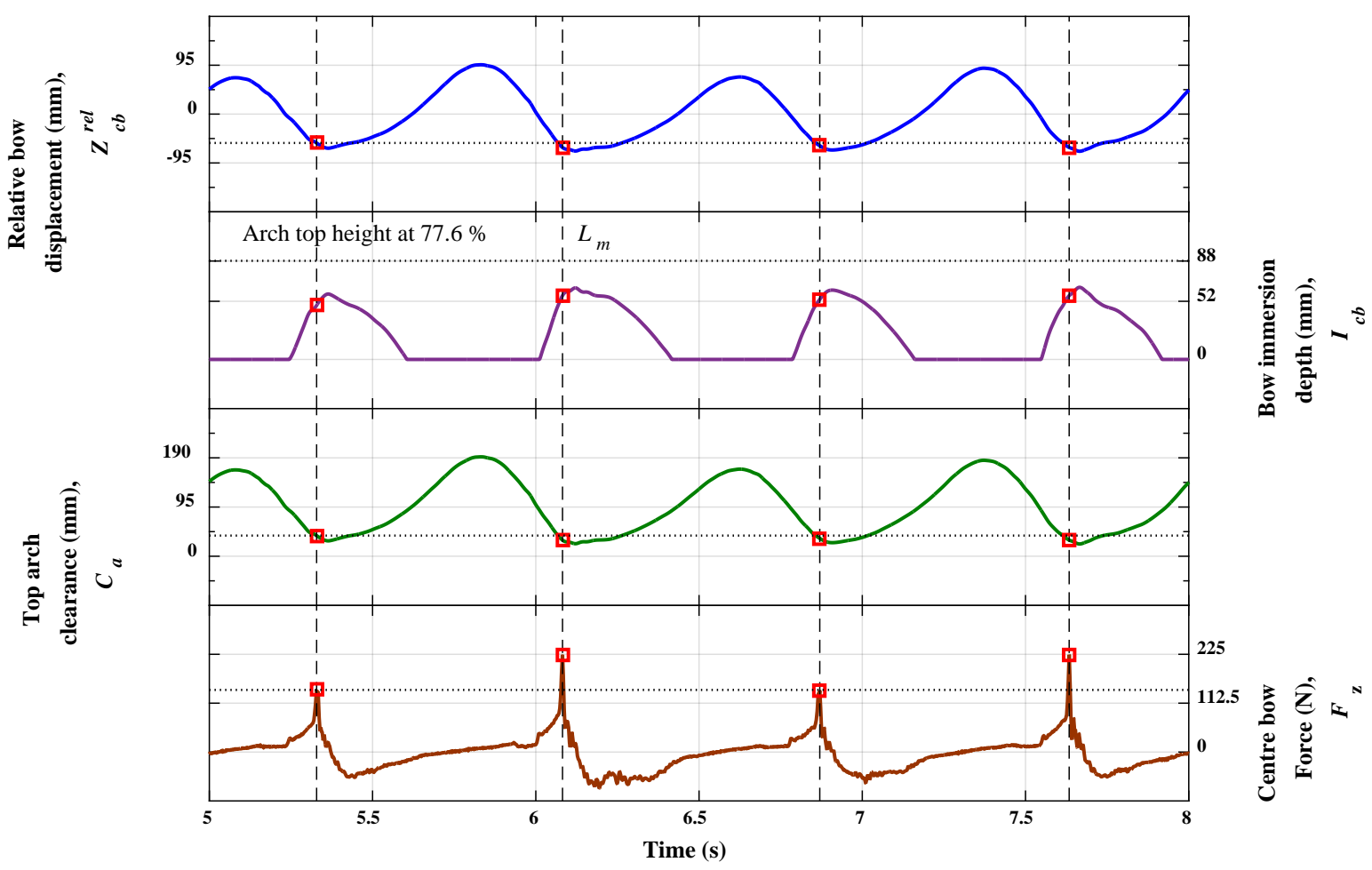

(b)

Figure 7 

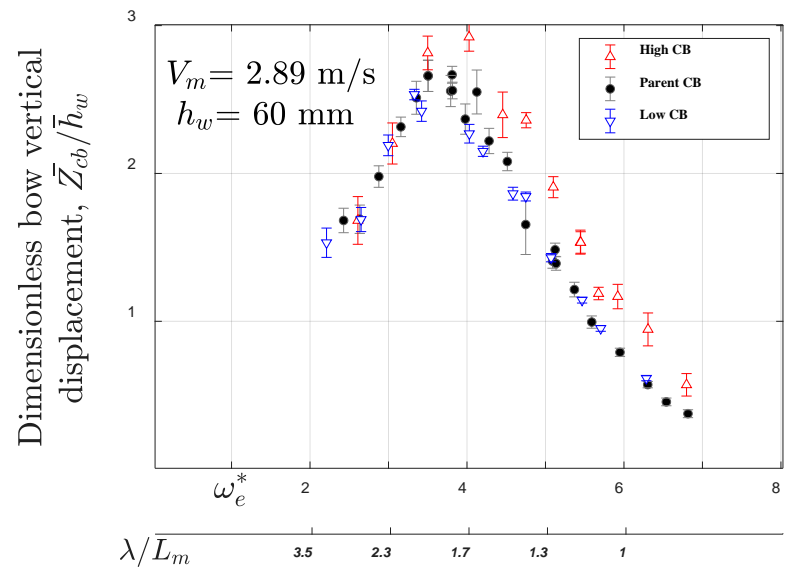

(a)

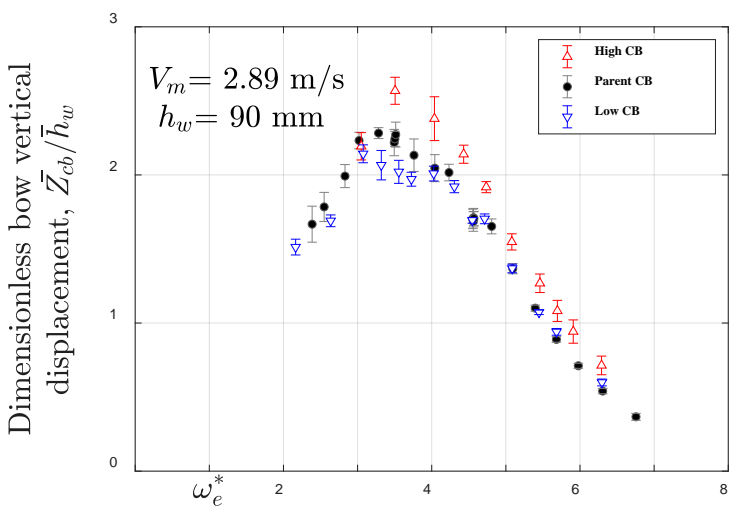

$\lambda / \overline{L_{m}}$

(b)

\section{Figure 8}




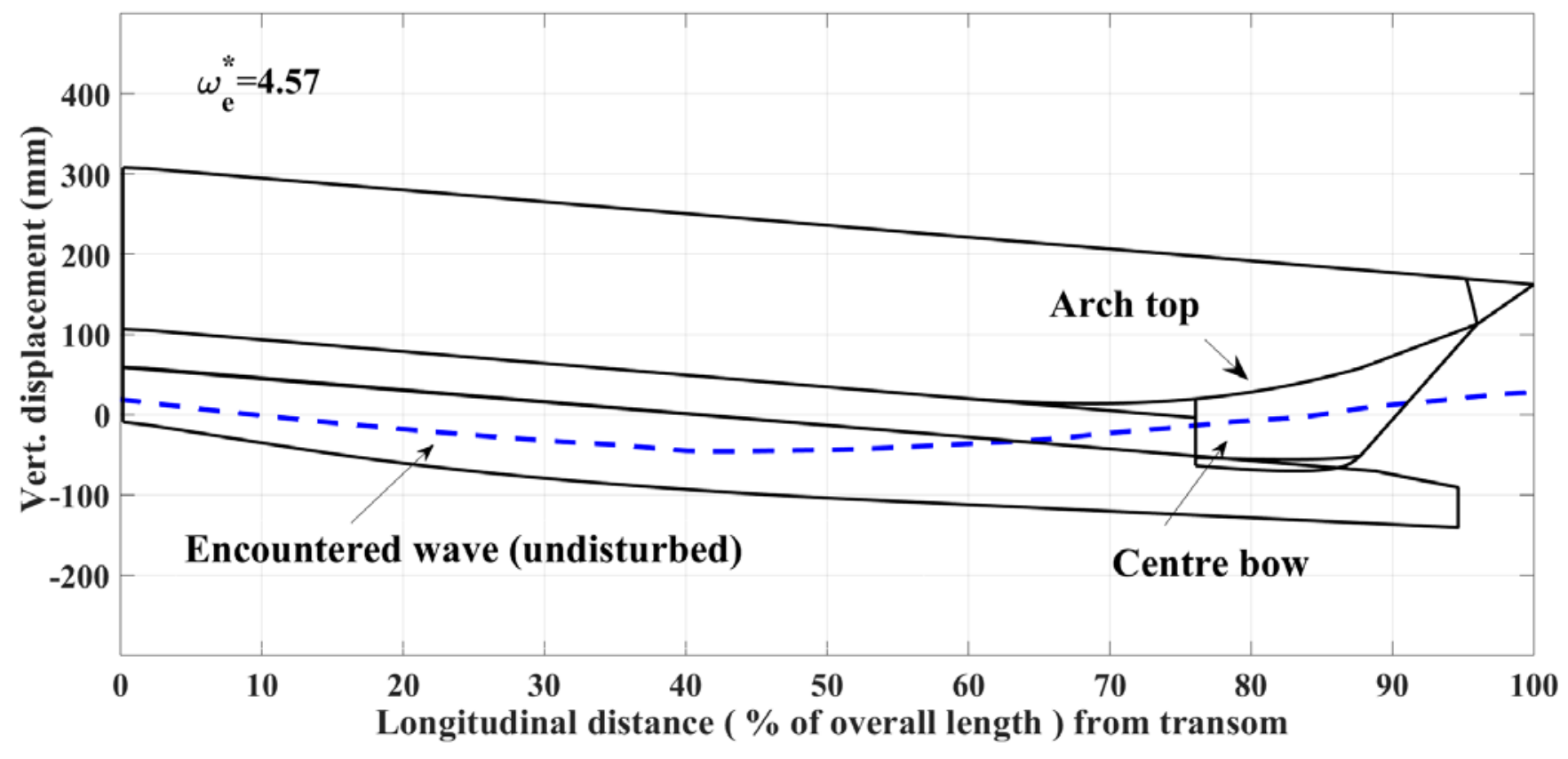

(a)

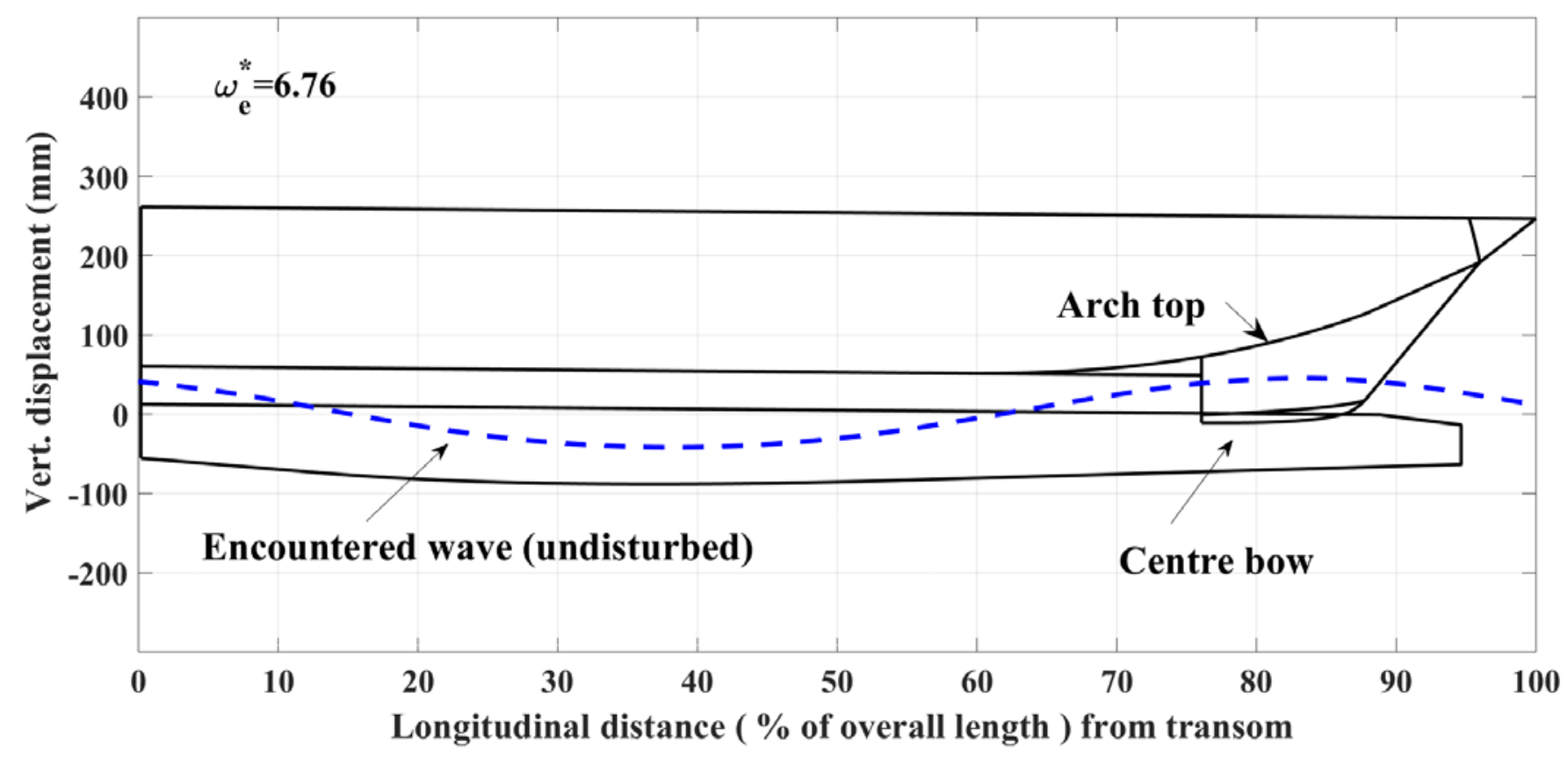

(b)

Figure 9 


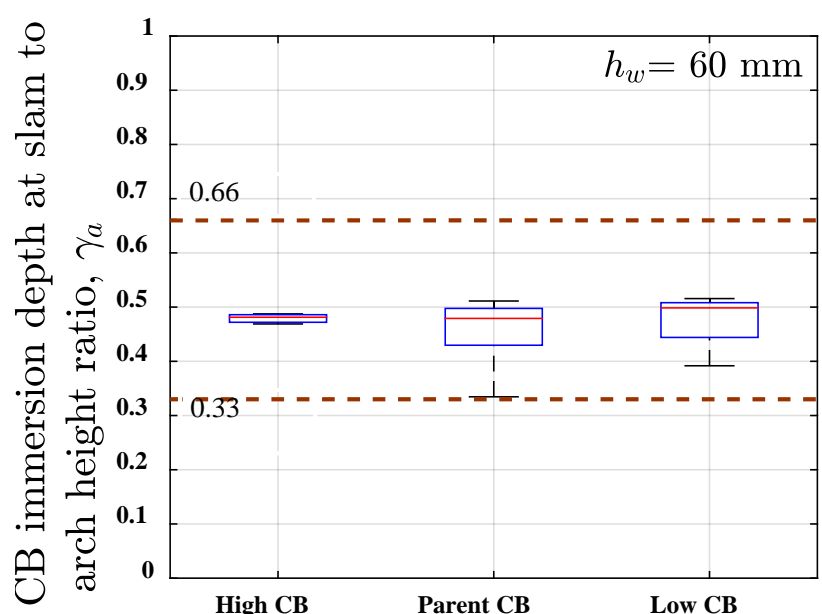

(a)

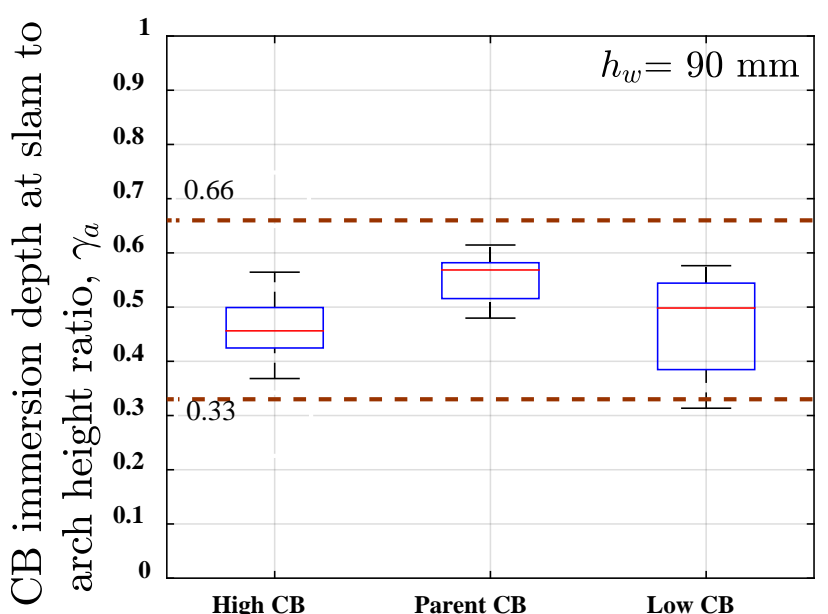

(b)

Figure 10 


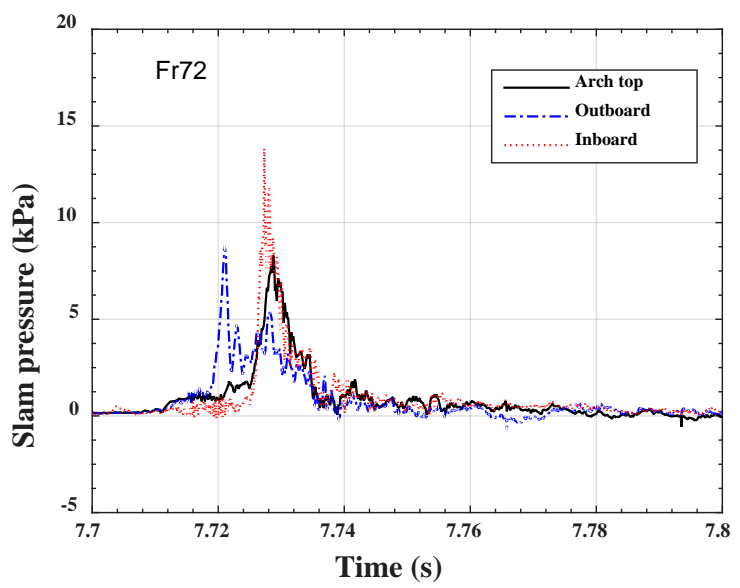

(a)

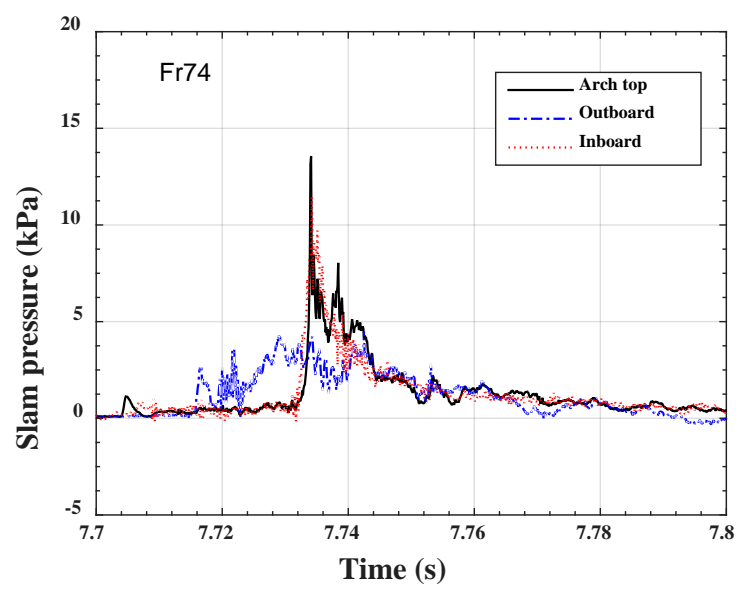

(c)

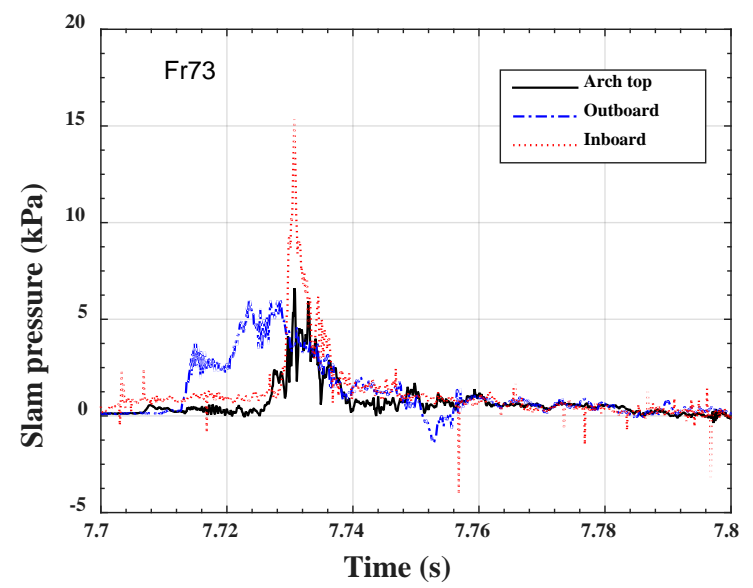

(b)

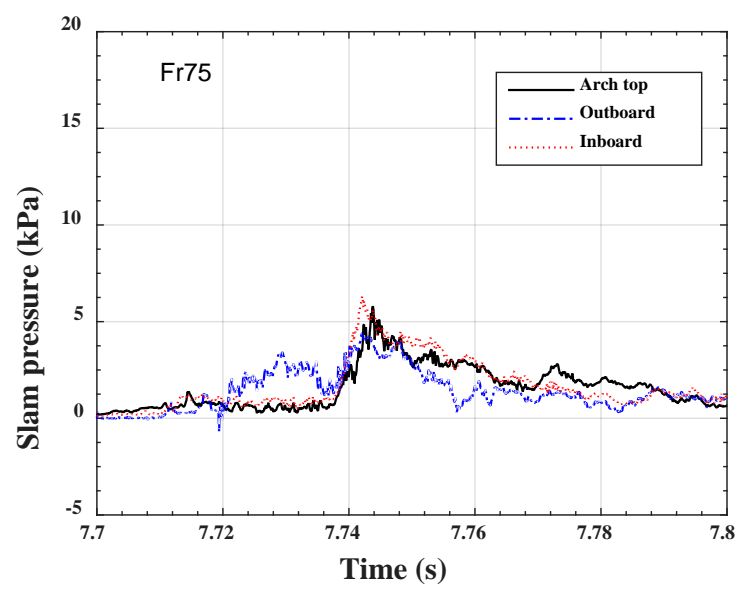

(d)

Figure 11 
(a)

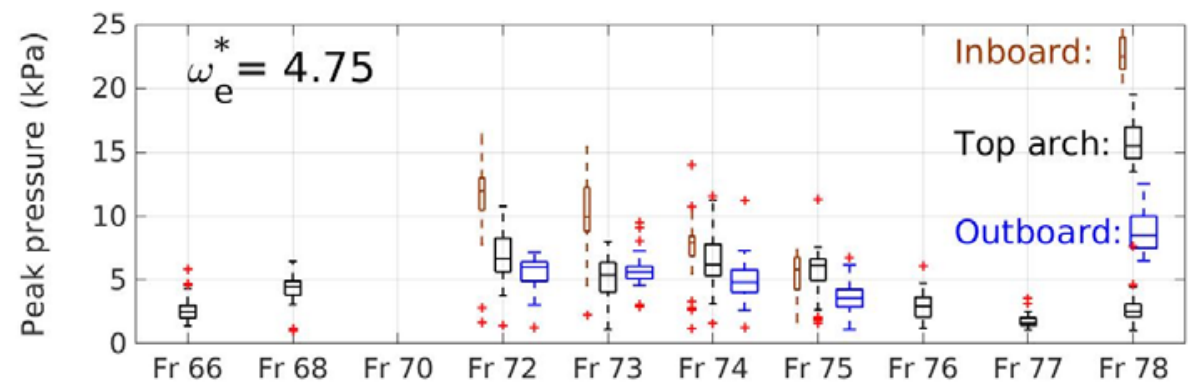

(b)

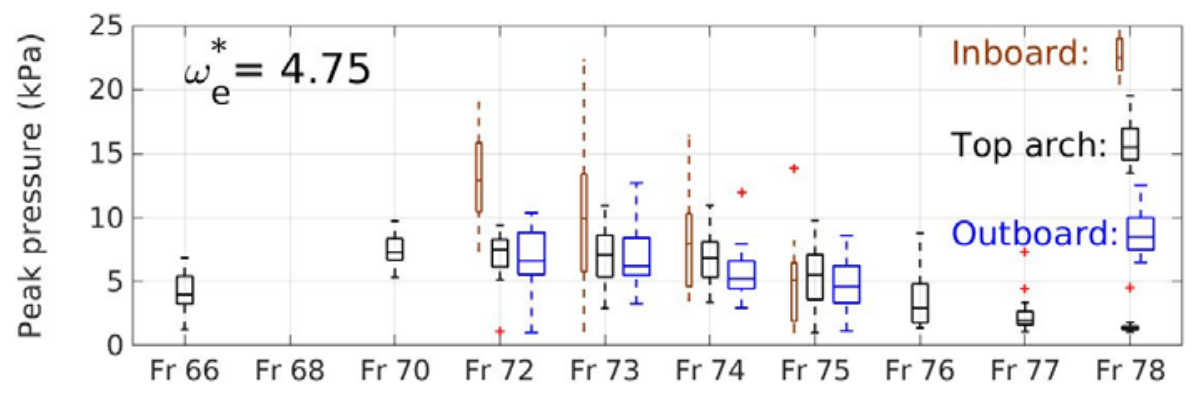

(c)

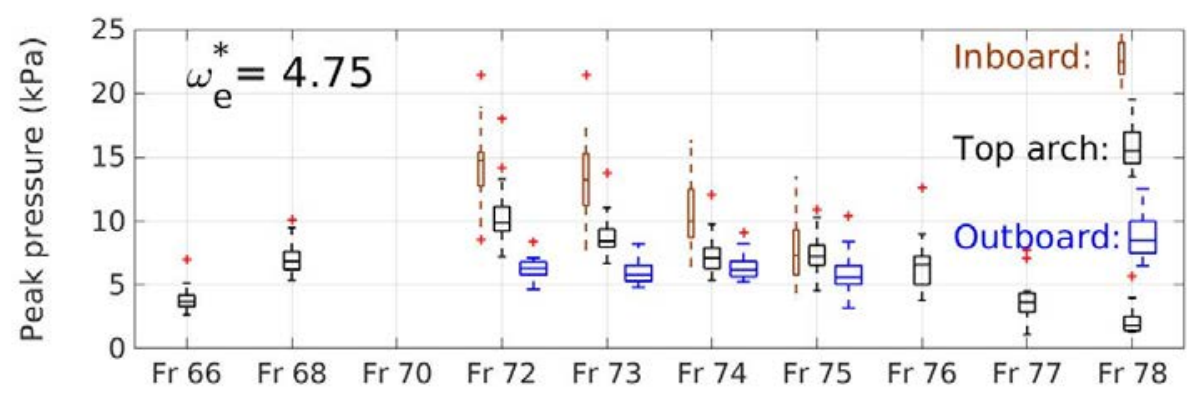

Figure 12 
(a)

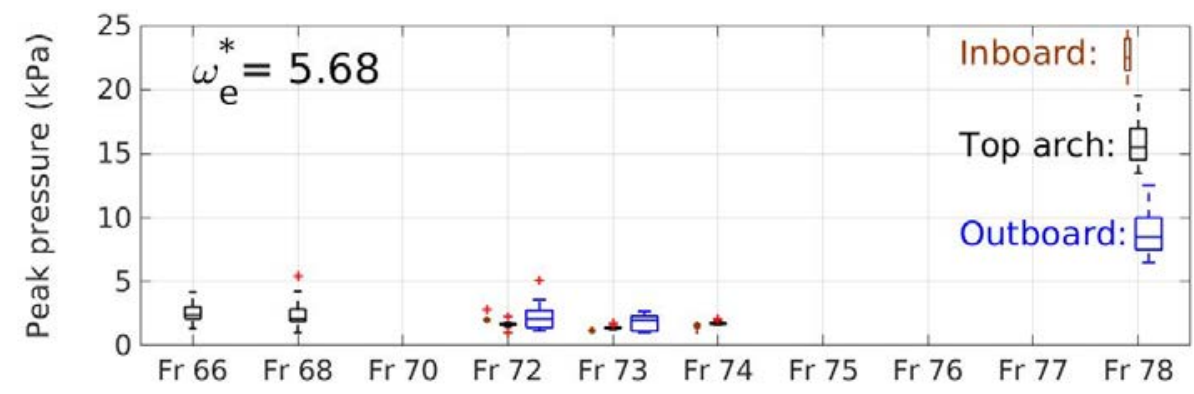

(b)

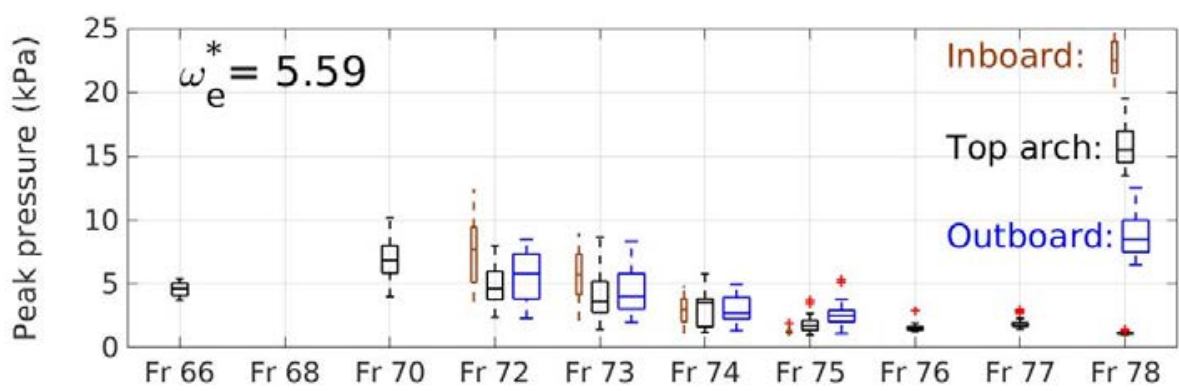

(c)

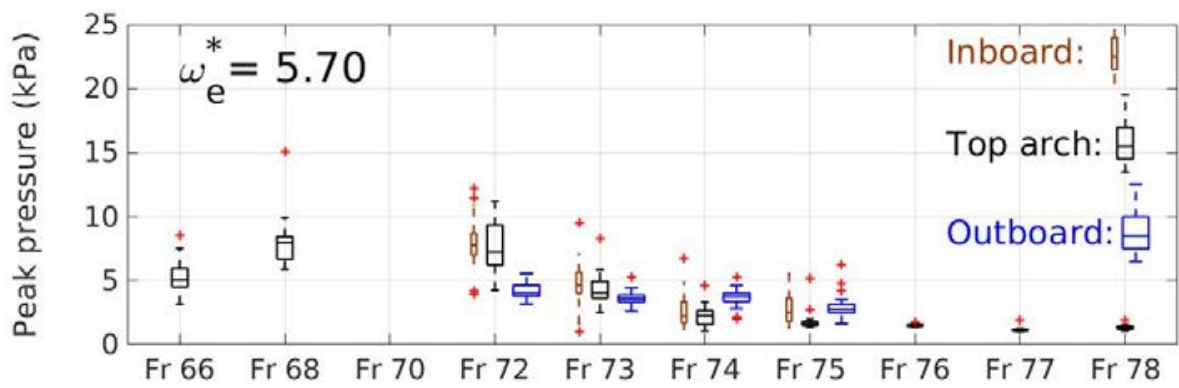

Figure 13 


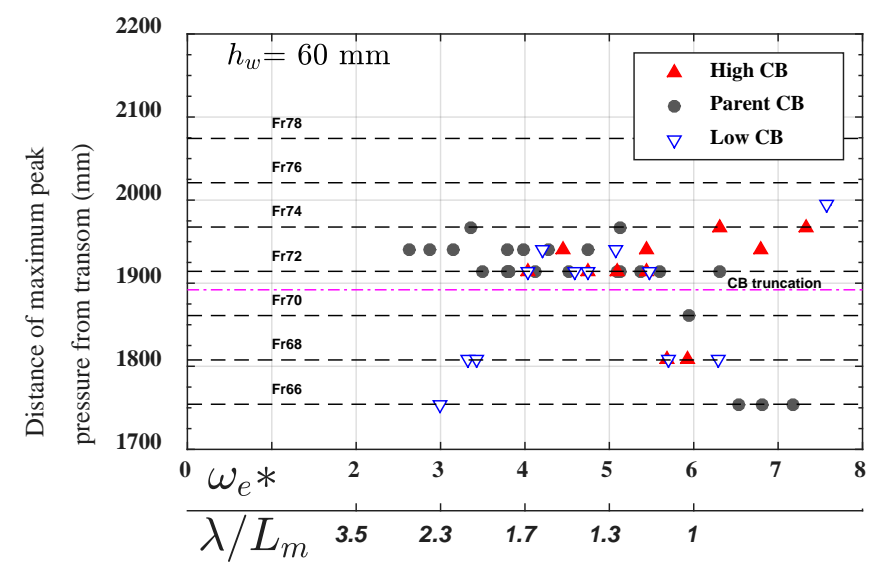

(a)

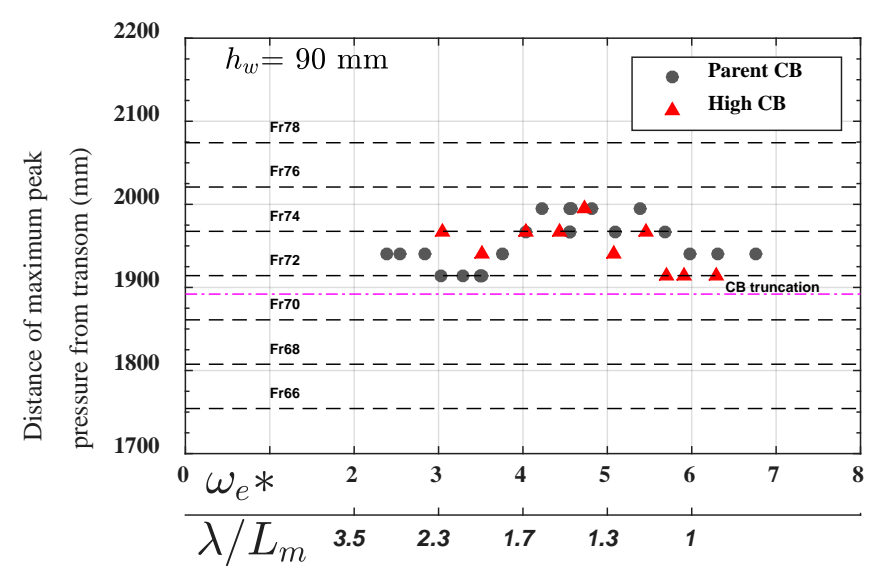

(c)

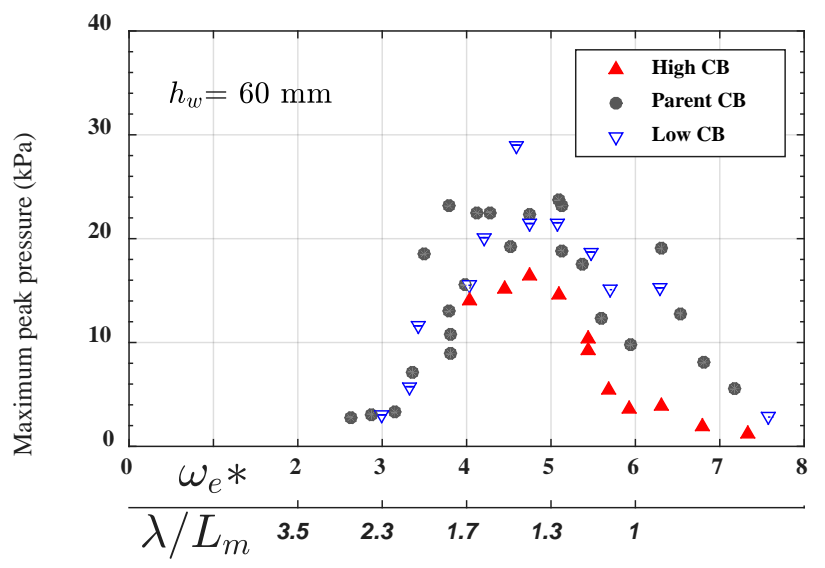

(b)

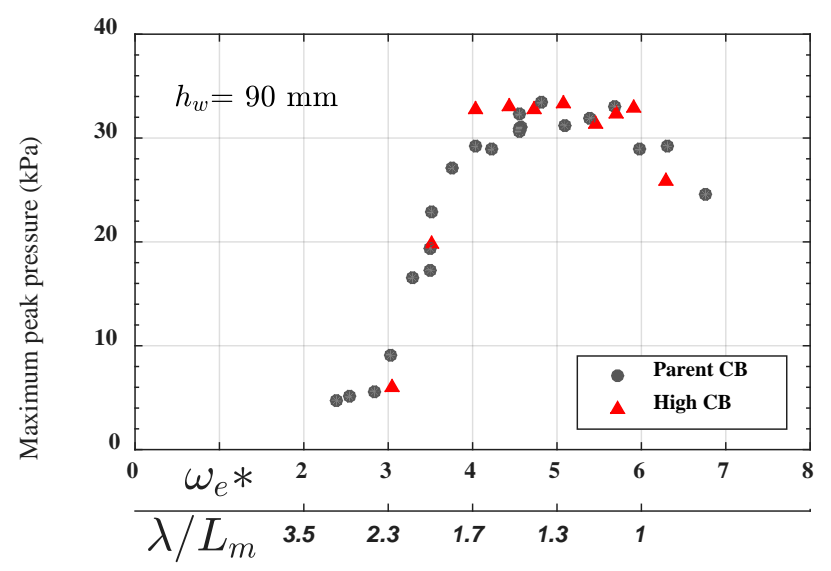

(d)

\section{Figure 14}




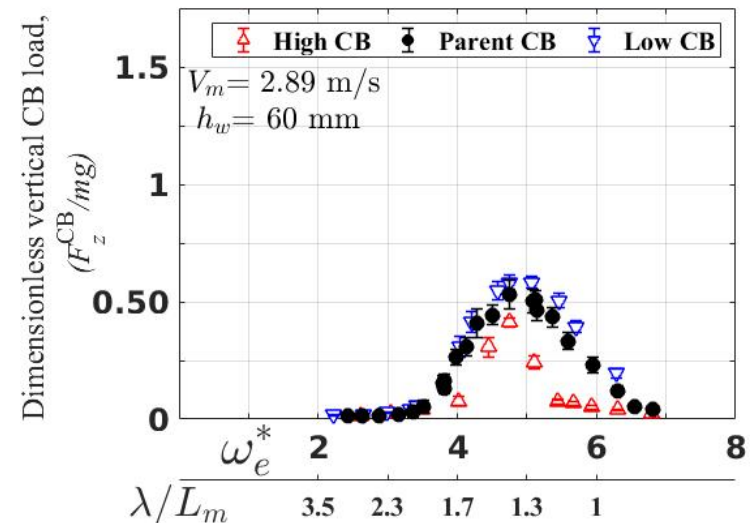

(a)

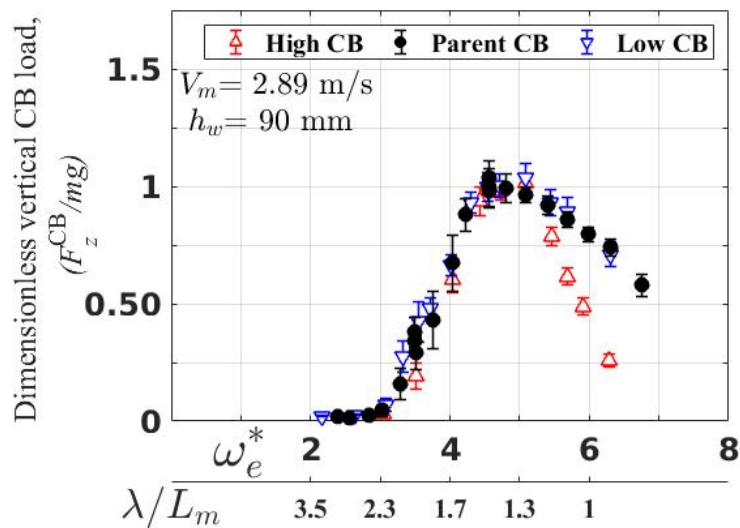

(b)

Figure 15 


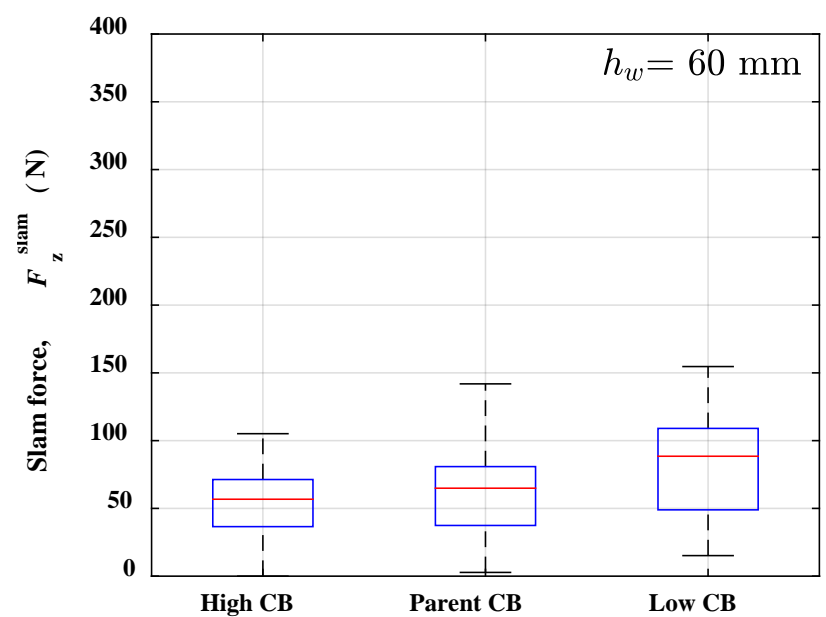

(a)

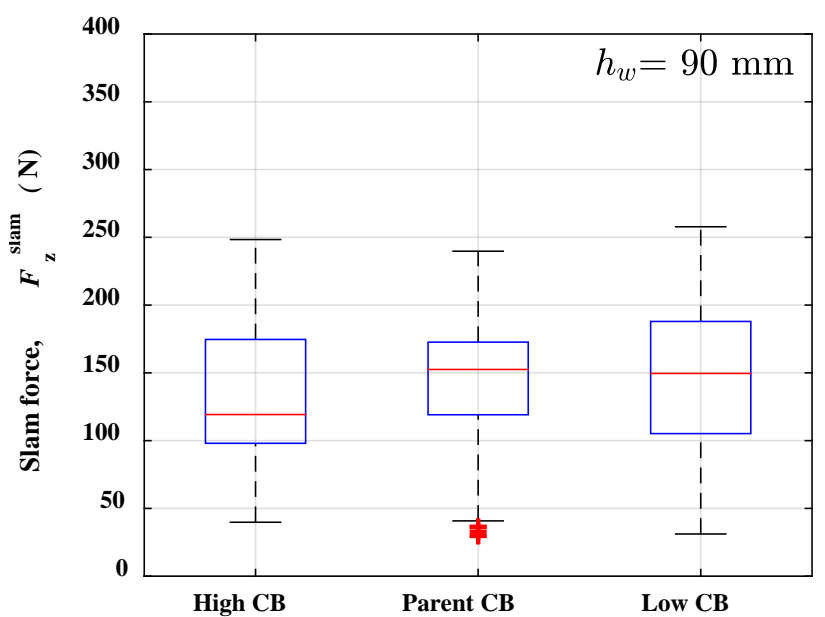

(b)

Figure 16 


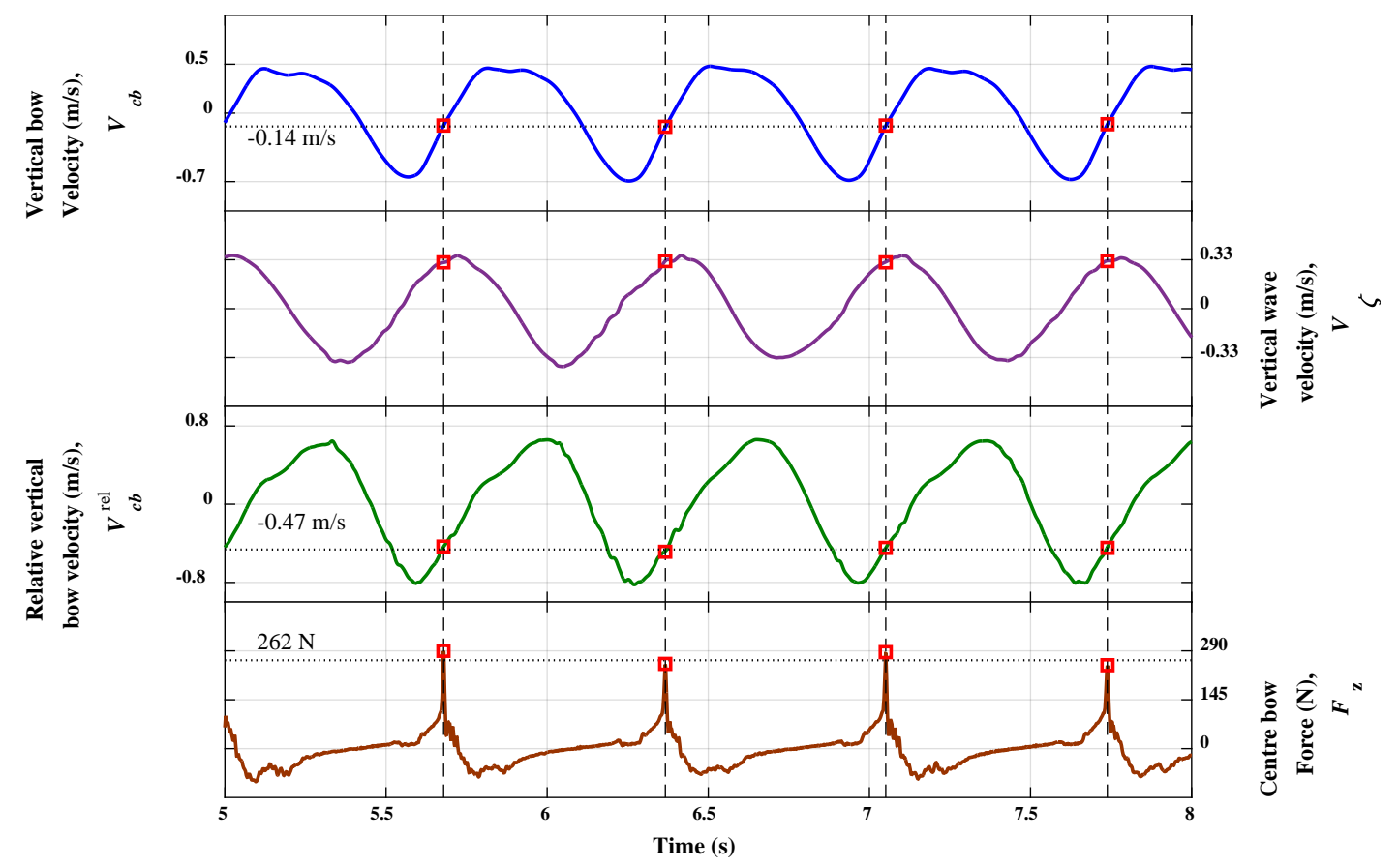

Figure 17 


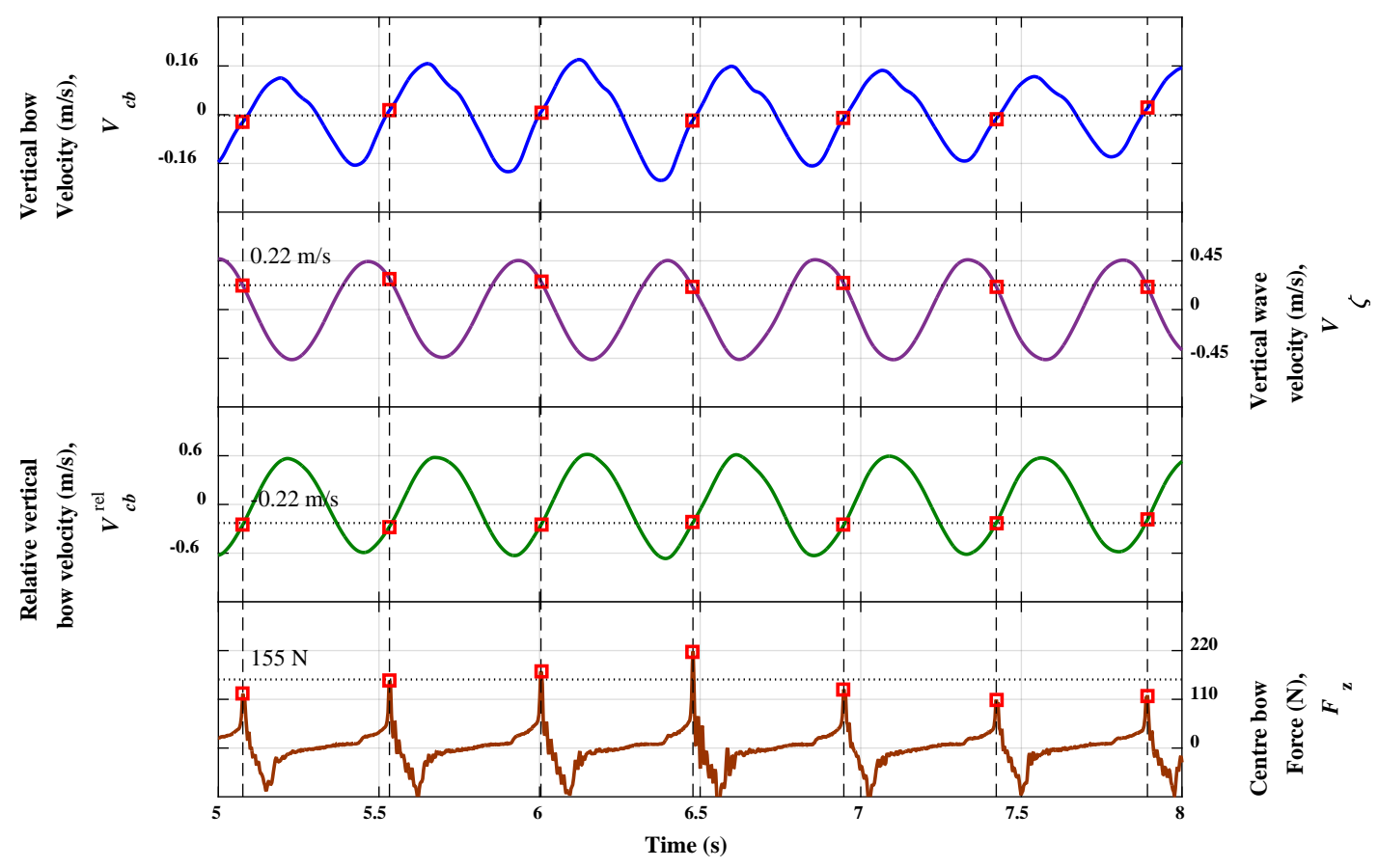

Figure 18

53 


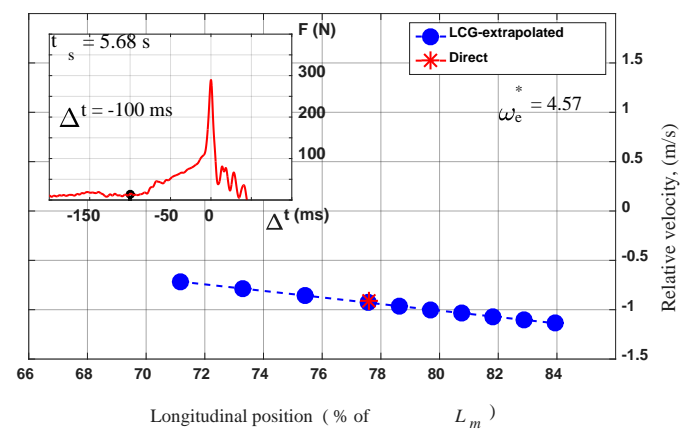

(a1)

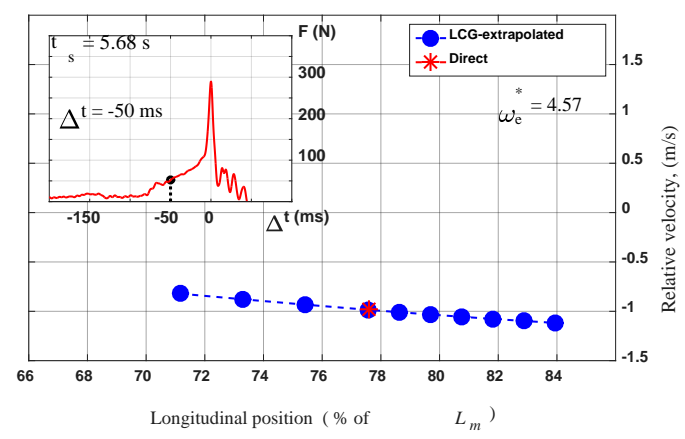

(a2)

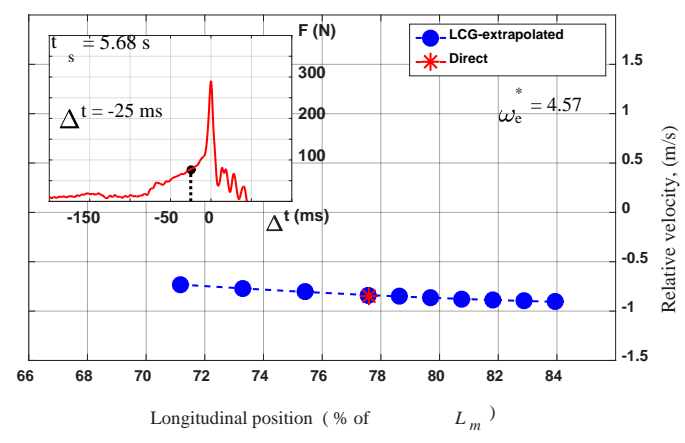

(a3)

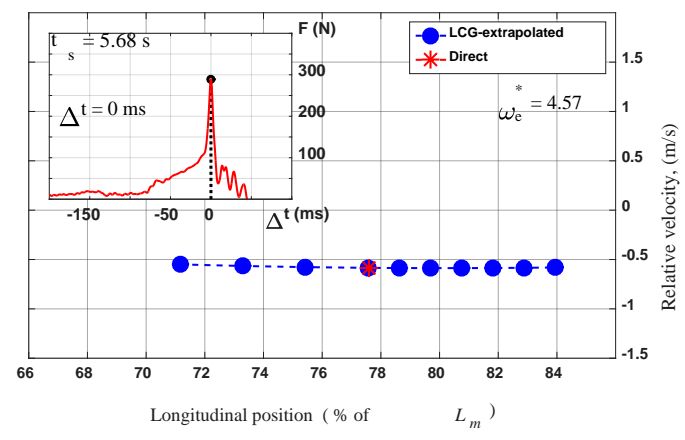

(a4)

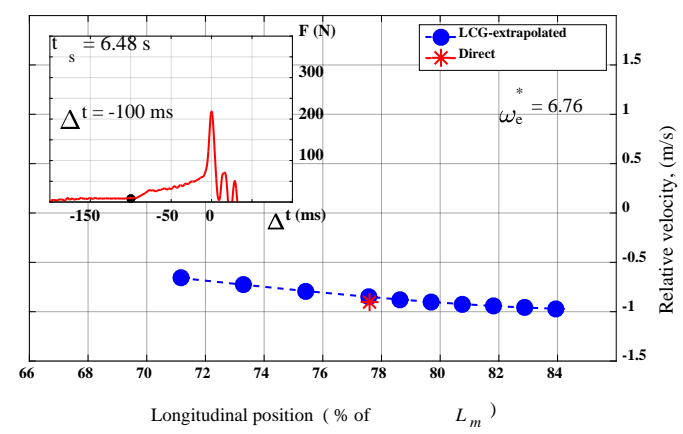

(b1)

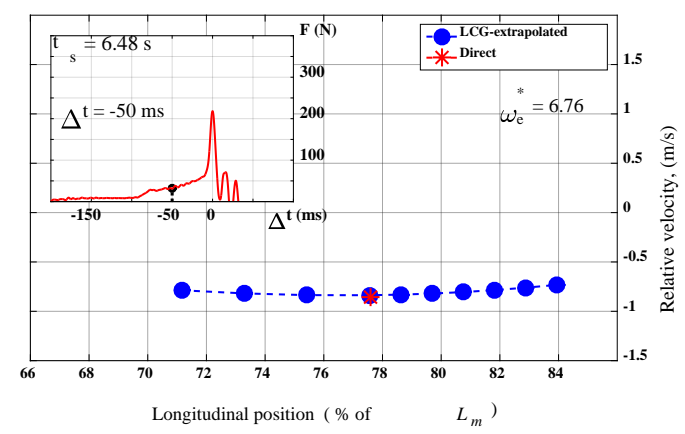

(b2)

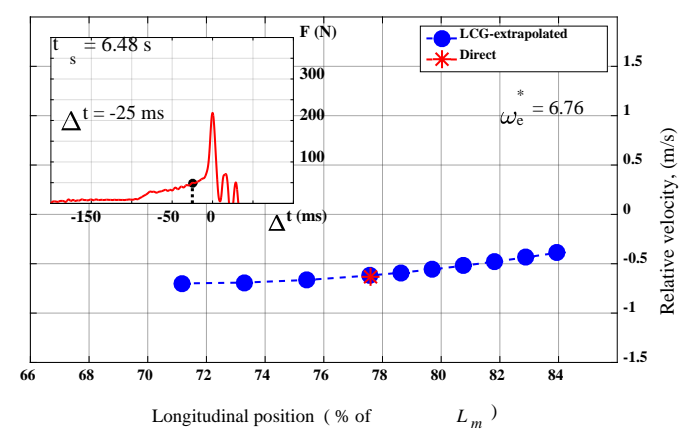

(b3)

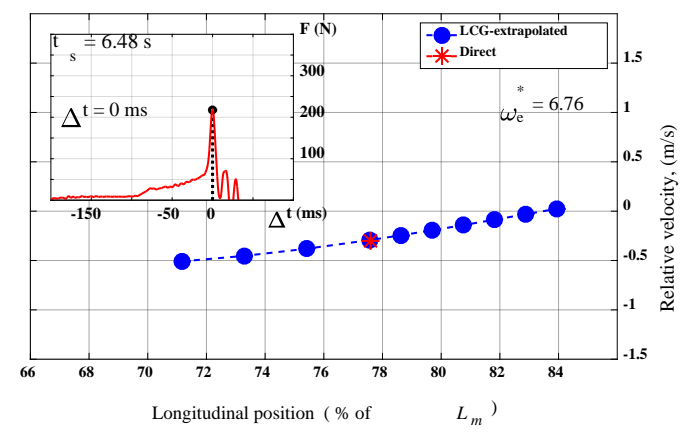

(b4)

Figure 19 


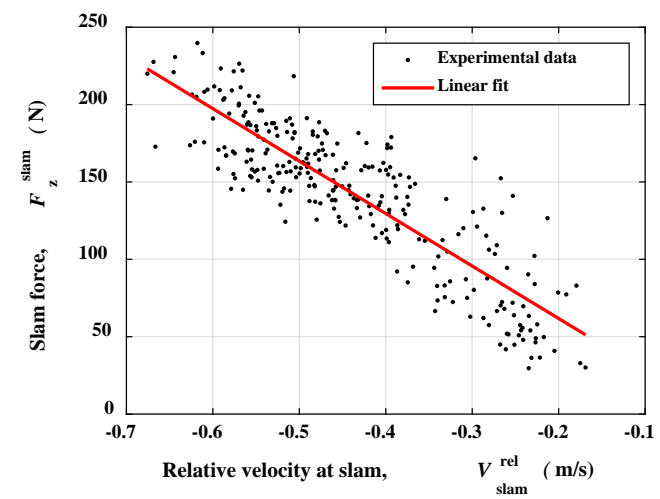

(a)

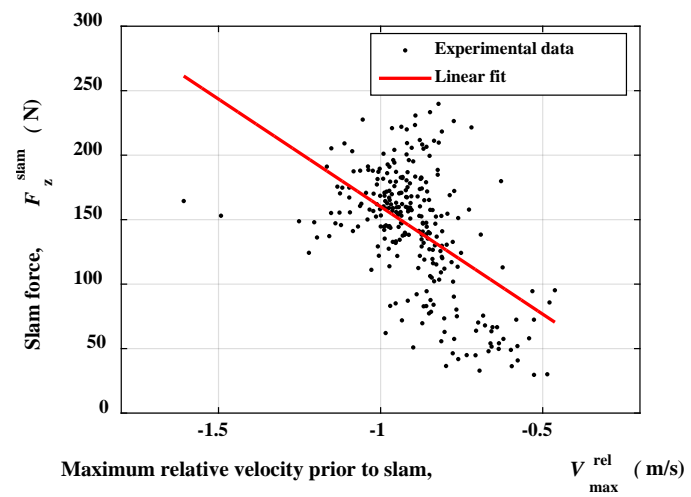

(b)

Figure 20 


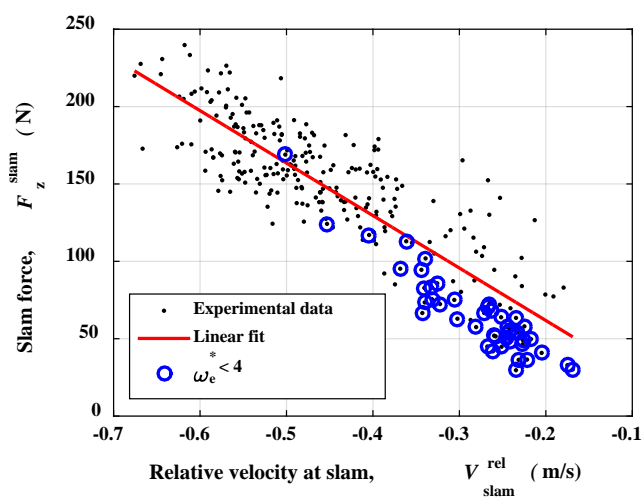

(a)

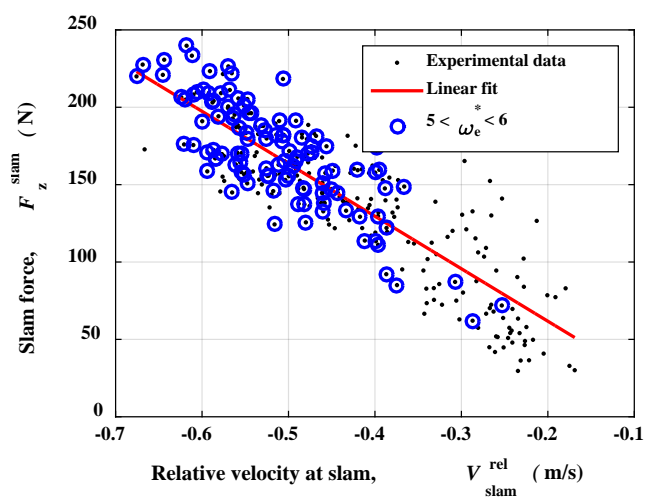

(c)

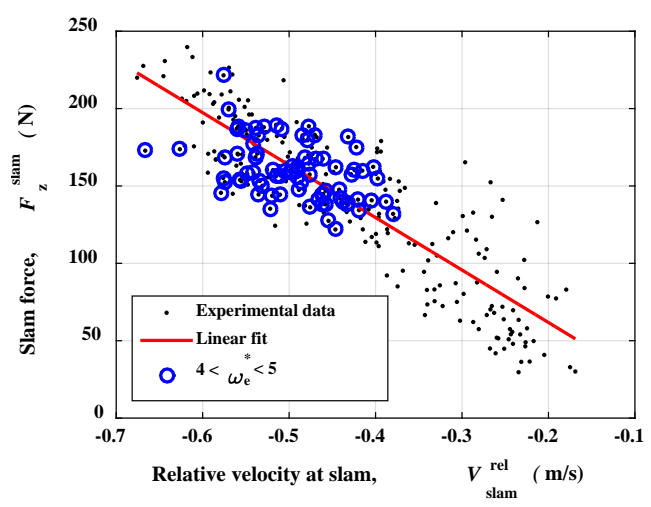

(b)

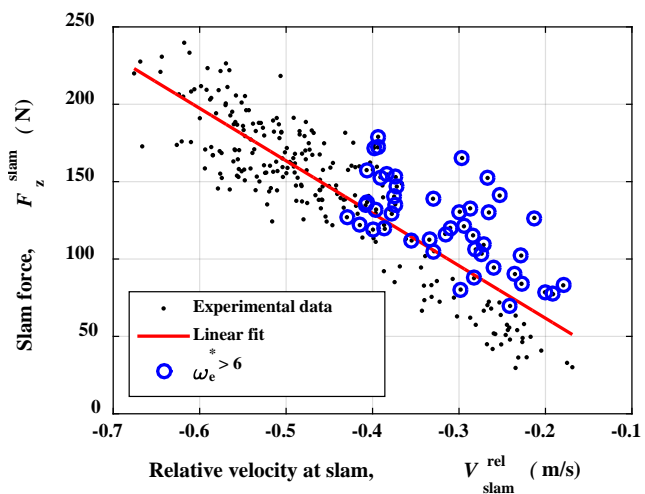

(d)

Figure 21 


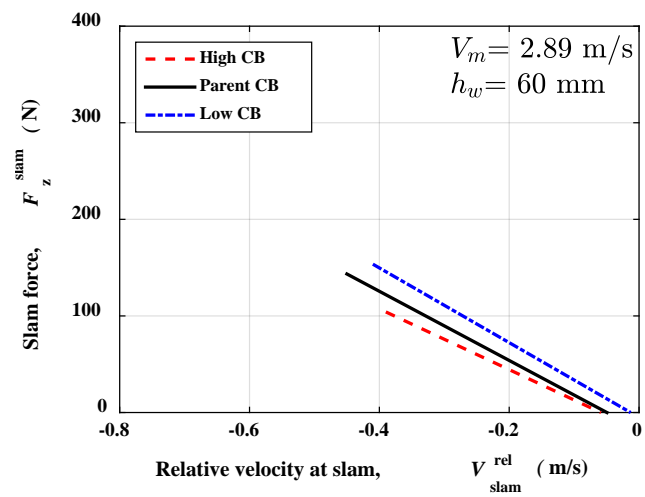

(a)

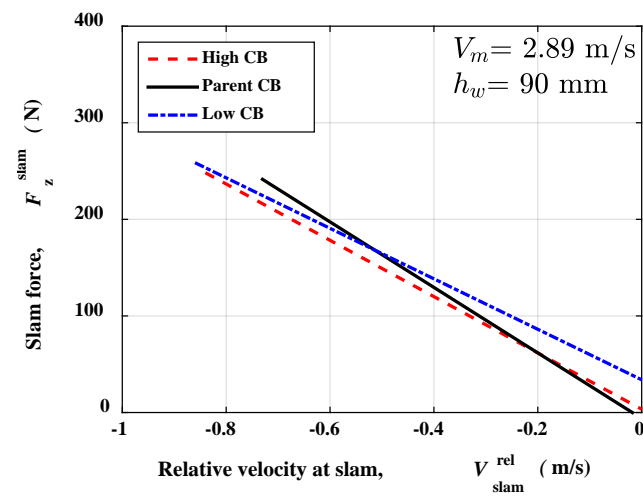

(b)

Figure 22 